San Jose State University

SJSU ScholarWorks

Mineta Transportation Institute Publications

$3-2022$

\title{
Examining the Effects of a Bike and E-Bike Lending Program on Commuting Behavior
}

\author{
Dillon T. Fitch \\ University of California, Davis \\ Zeyu Gao \\ University of California, Davis \\ Lucy Noble \\ Mineta Transportation Institute \\ Terry Mac \\ Mineta Transportation Institute
}

Follow this and additional works at: https://scholarworks.sjsu.edu/mti_publications

Part of the Infrastructure Commons, and the Transportation Commons

\section{Recommended Citation \\ Dillon T. Fitch, Zeyu Gao, Lucy Noble, and Terry Mac. "Examining the Effects of a Bike and E-Bike Lending Program on Commuting Behavior" Mineta Transportation Institute Publications (2022). https://doi.org/ 10.31979/mti.2022.2051}

This Report is brought to you for free and open access by SJSU ScholarWorks. It has been accepted for inclusion in Mineta Transportation Institute Publications by an authorized administrator of SJSU ScholarWorks. For more information, please contact scholarworks@sjsu.edu. 
SJSU SAN Soses STARE

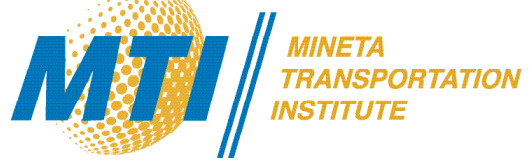

Examining the Effects of a Bike and E-Bike Lending Program on Commuting Behavior

Dillon T. Fitch Zeyu Gao Lucy Noble Terry Mac

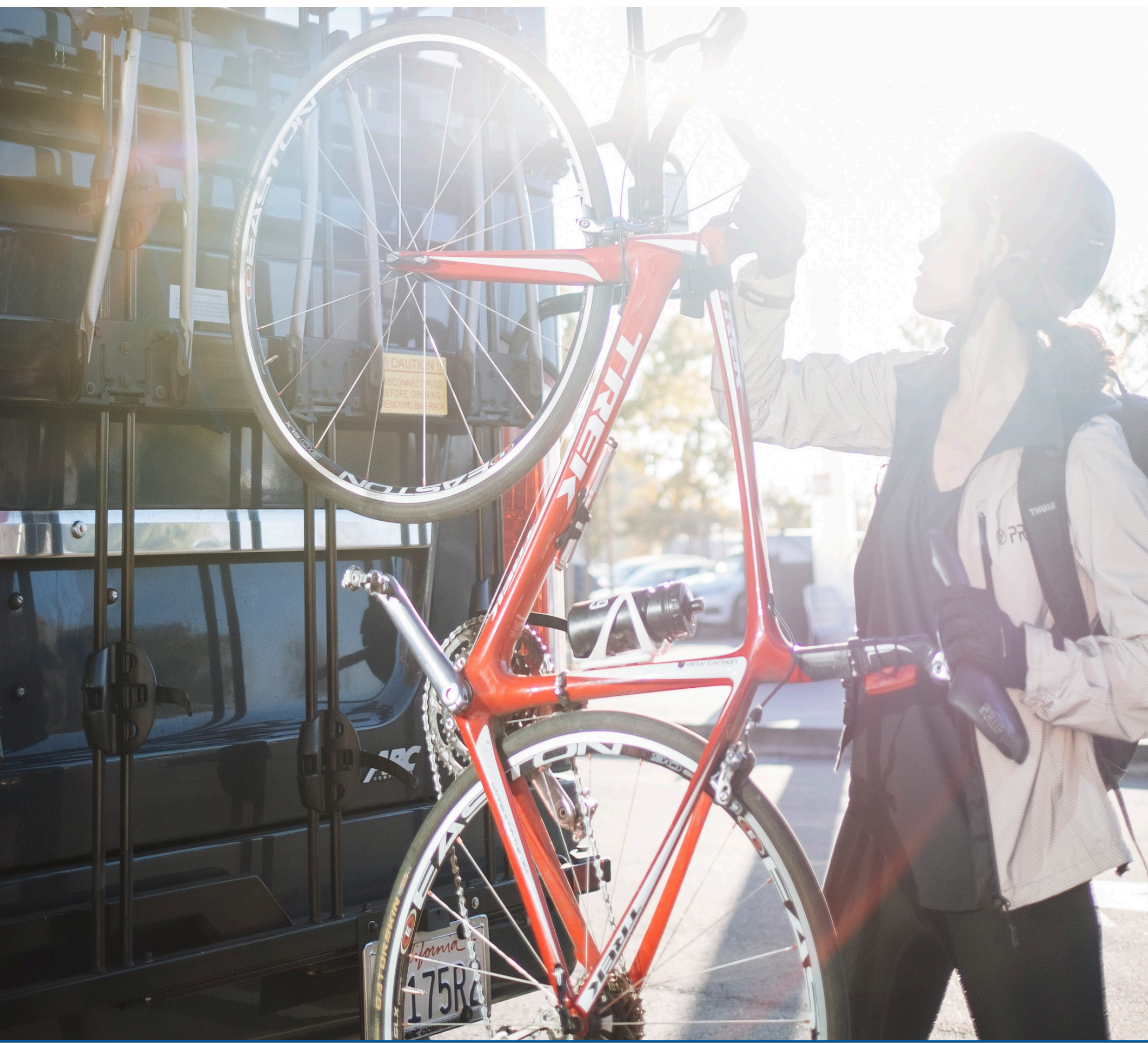




\section{Mineta Transportation Institute}

Founded in 1991, the Mineta Transportation Institute (MTI), an organized research and training unit in partnership with the Lucas College and Graduate School of Business at San José State University (SJSU), increases mobility for all by improving the safety, efficiency, accessibility, and convenience of our nation's transportation system. Through research, education, workforce development, and technology transfer, we help create a connected world. MTI leads the Mineta Consortium for Transportation Mobility (MCTM) funded by the U.S. Department of Transportation and the California State University Transportation Consortium (CSUTC) funded by the State of California through Senate Bill 1. MTI focuses on three primary responsibilities:

\section{Research}

MTI conducts multi-disciplinary research focused on surface transportation that contributes to effective decision making. Research areas include: active transportation; planning and policy; security and counterterrorism; sustainable transportation and land use; transit and passenger rail; transportation engineering; transportation finance; transportation technology; and workforce and labor. MTI research publications undergo expert peer review to ensure the quality of the research.

\section{Education and Workforce}

To ensure the efficient movement of people and products, we must prepare a new cohort of transportation professionals who are ready to lead a more diverse, inclusive, and equitable transportation industry. To help achieve this, MTI sponsors a suite of workforce development and education opportunities. The Institute supports educational programs offered by the
Lucas Graduate School of Business: a Master of Science in Transportation Management, plus graduate certificates that include High-Speed and Intercity Rail Management and Transportation Security Management. These flexible programs offer live online classes so that working transportation professionals can pursue an advanced degree regardless of their location.

\section{Information and Technology Transfer}

MTI utilizes a diverse array of dissemination methods and media to ensure research results reach those responsible for managing change. These methods include publication, seminars, workshops, websites, social media, webinars, and other technology transfer mechanisms. Additionally, MTI promotes the availability of completed research to professional organizations and works to integrate the research findings into the graduate education program. MTI's extensive collection of transportation-related publications is integrated into San José State University's world-class Martin Luther King, Jr. Library.

\section{Disclaimer}

The contents of this report reflect the views of the authors, who are responsible for the facts and accuracy of the information presented herein. This document is disseminated in the interest of information exchange. MTI's research is funded, partially or entirely, by grants from the California Department of Transportation, the California State University Office of the Chancellor, the U.S. Department of Homeland Security, and the U.S. Department of Transportation, who assume no liability for the contents or use thereof. This report does not constitute a standard specification, design standard, or regulation. 
Report 22-07

\title{
Examining the Effects of a Bike and E-Bike Lending Program on Commuting Behavior
}

\author{
Dillon T. Fitch \\ Zeyu Gao Lucy \\ Noble Terry \\ Mac
}

March 2022

A publication of the

Mineta Transportation Institute

Created by Congress in 1991

College of Business

San José State University

San José, CA 95192-0219 


\section{TECHNICAL REPORT \\ DOCUMENTATION PAGE}

\begin{tabular}{|c|c|c|c|}
\hline $\begin{array}{l}\text { 1. Report No. } \\
22-07\end{array}$ & 2. Government Accession No. & \multicolumn{2}{|c|}{ 3. Recipient's Catalog No. } \\
\hline \multirow{2}{*}{\multicolumn{2}{|c|}{$\begin{array}{l}\text { 4. Title and Subtitle } \\
\text { Examining the Effects of a Bike and E-Bike Lending Program on Commuting } \\
\text { Behavior }\end{array}$}} & \multicolumn{2}{|l|}{$\begin{array}{l}\text { 5. Report Date } \\
\text { March } 2022\end{array}$} \\
\hline & & \multicolumn{2}{|c|}{ 6. Performing Organization Code } \\
\hline \multicolumn{2}{|l|}{$\begin{array}{l}\text { 7. Authors } \\
\text { Dillon T. Fitch } \\
\text { Zeyu Gao } \\
\text { Lucy Noble } \\
\text { Terry Mac }\end{array}$} & \multicolumn{2}{|c|}{$\begin{array}{l}\text { 8. Performing Organization Report } \\
\text { CA-MTI-2051 }\end{array}$} \\
\hline \multirow{2}{*}{\multicolumn{2}{|c|}{$\begin{array}{l}\text { 9. Performing Organization Name and Address } \\
\text { Mineta Transportation Institute } \\
\text { College of Business } \\
\text { San José State University } \\
\text { San José, CA 95192-0219 }\end{array}$}} & \multicolumn{2}{|c|}{ 10. Work Unit No. } \\
\hline & & \multicolumn{2}{|c|}{ 11. Contract or Grant No. } \\
\hline \multirow{2}{*}{\multicolumn{2}{|c|}{ 12. Sponsoring Agency Name and Address }} & \multicolumn{2}{|c|}{$\begin{array}{l}\text { 13. Type of Report and Period } \\
\text { Covered }\end{array}$} \\
\hline & & \multicolumn{2}{|c|}{ 14. Sponsoring Agency Code } \\
\hline \multicolumn{4}{|l|}{ 15. Supplemental Notes } \\
\hline \multicolumn{4}{|c|}{$\begin{array}{l}\text { 16. Abstract } \\
\text { In 2015, Google added a new transportation demand management (TDM) program to increase bike commuting to their } \\
\text { two main campuses in Mountain View and Sunnyvale, California. An initial survey of employees indicated that bike } \\
\text { ownership and worry about maintenance were primary bicycling barriers. With this information, Google began a program } \\
\text { that loaned high-quality electric-assisted and conventional bicycles for a period of six months at no cost to interested } \\
\text { employees. This research evaluates the effectiveness of the program at changing travel behavior to the corporate campuses } \\
\text { by using self-reported and smartphone-integrated travel data. The lending program at Google represents one of, if not the } \\
\text { largest, employer-sponsored bike and e-bike lending program in North America with over 1,000 bikes in its inventory. Thus, } \\
\text { the evaluation of this program is a critical first step for understanding how bike lending can influence travel behavior in } \\
\text { North American suburban contexts. }\end{array}$} \\
\hline $\begin{array}{l}\text { 17. Key Words } \\
\text { Transportation demand management, } \\
\text { Bicycling, bike lending, e-bike, commute } \\
\text { behavior }\end{array}$ & \multicolumn{3}{|c|}{$\begin{array}{l}\text { 18. Distribution Statement } \\
\text { No restrictions. This document is available to the public through The } \\
\text { National Technical Information Service, Springfield, VA } 22161 .\end{array}$} \\
\hline $\begin{array}{l}\text { 19. Security Classif. (of this report) } \\
\text { Unclassified }\end{array}$ & $\begin{array}{l}\text { 20. Security Classif. (of this page) } \\
\text { Unclassified }\end{array}$ & $\begin{array}{l}\text { 21. No. of Pages } \\
58\end{array}$ & 22. Price \\
\hline
\end{tabular}

Form DOT F 1700.7 (8-72) 
Copyright (C) 2022

\section{by Mineta Transportation Institute}

All rights reserved.

DOI: $10.31979 / \mathrm{mti} .2022 .2051$

Mineta Transportation Institute College of Business

San José State University

San José, CA 95192-0219

Tel: (408) 924-7560

Fax: (408) 924-7565

Email: mineta-institute@sjsu.edu

transweb.sjsu.edu/research/2051-Ebike-Employer transweb.sjsu.edu/research/2051 


\section{CONTENTS}

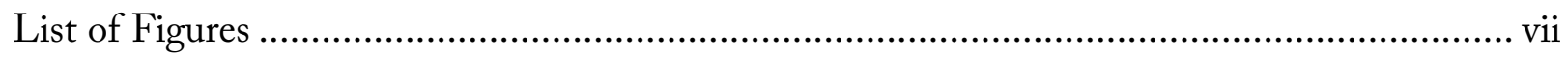

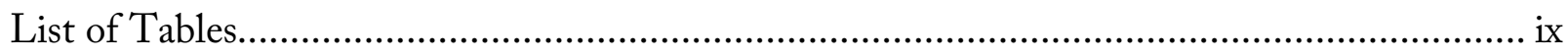

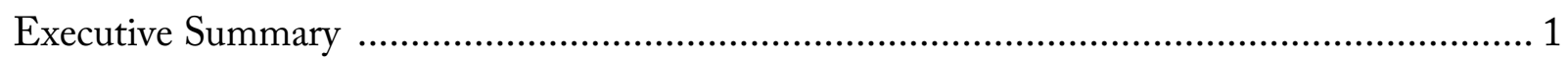

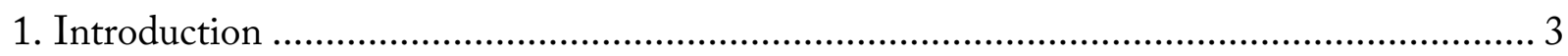

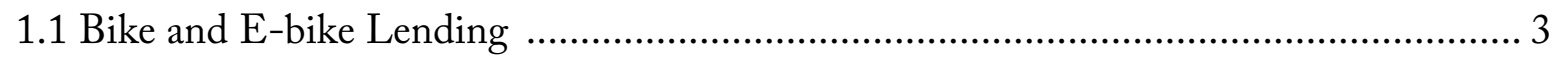

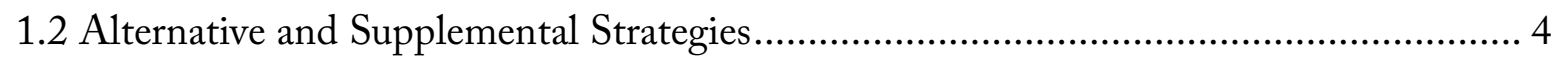

1.3 Case Study: Google Bike Commuter Program (Bike and E-bike lending).................... 5

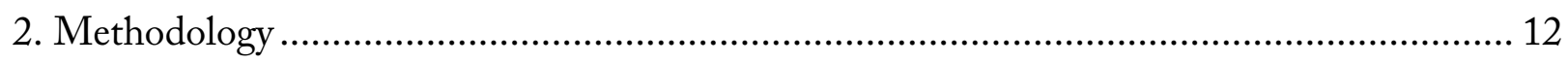

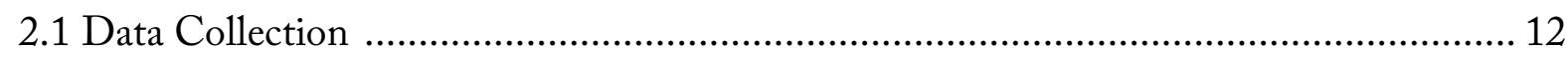

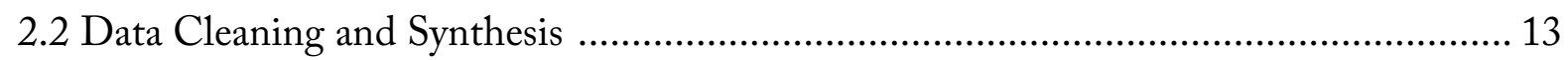

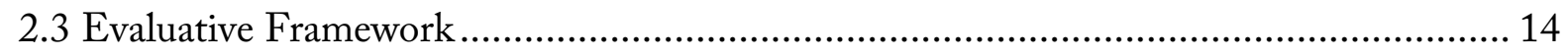

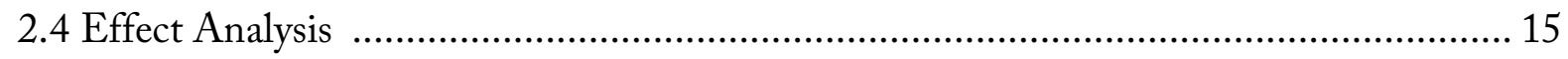

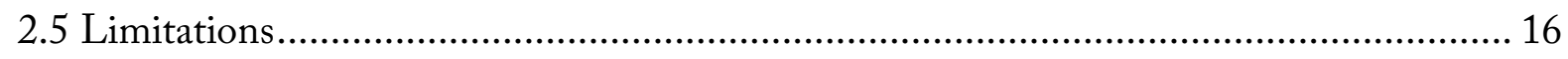

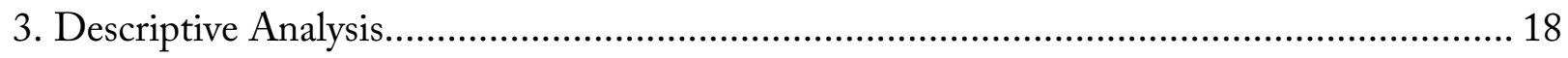

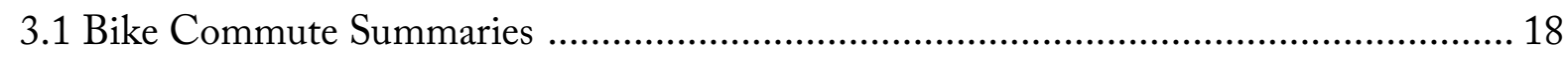

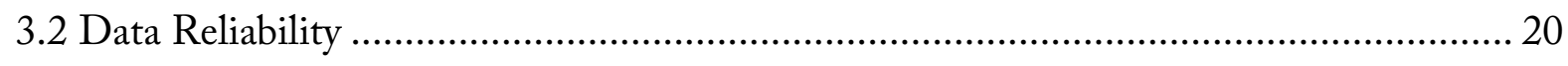

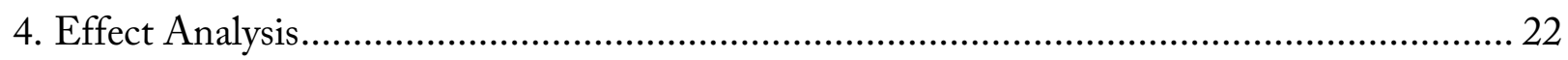

4.1 Model Results and Influential Variables ................................................................. 22

4.2 Effects of the Program on Bicycling to Work ............................................................... 30

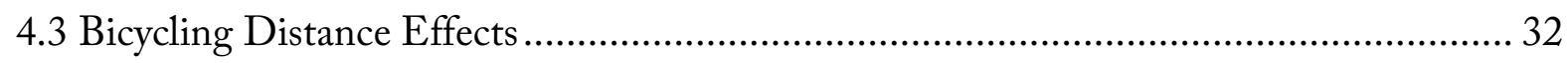

4.4 Effects of the Program on SOV Commuting to Work .................................................. 34 


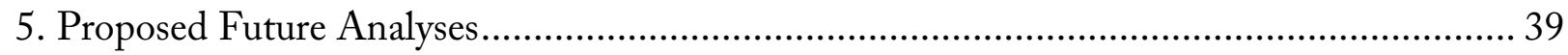

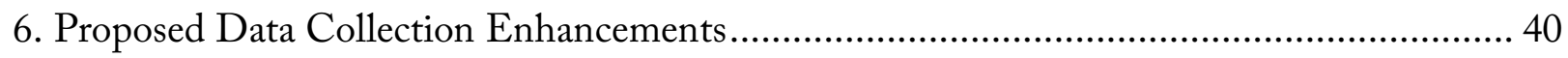

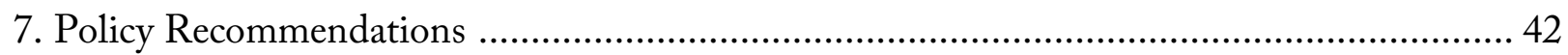

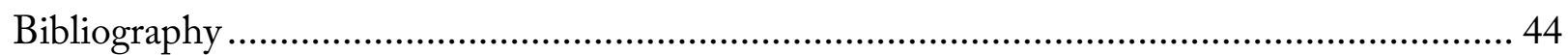

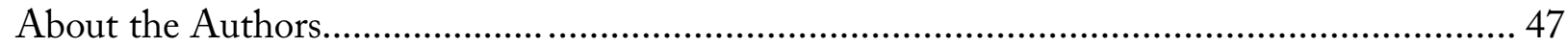




\section{LIST OF FIGURES}

Figure 1. Google Commuting Mode Split from the 2019 Google Commute Survey .............. 6

Figure 2. Data Cleaning and Synthesis Process................................................................. 14

Figure 3. Histograms of Person-Level Average Weekly Morning Bike Commutes by Project Phase.................................................................................................... 18

Figure 4. Histograms of Person-Level Average Weekly Morning Bike Commutes by Project Phase (Row Panels) and by Self-Reported Bike Commute Frequency (Column Panels) Before Participation....................................................................................... 19

Figure 5. Self-Reported Vs. Strava Measured Commute Distance ......................................... 21

Figure 6. Model Predicted Person-Level Bike-to-Work Rate During the Program ................. 26

Figure 7. Model Predicted Mean Bike-to-Work Rate of Bike-Lending Participants

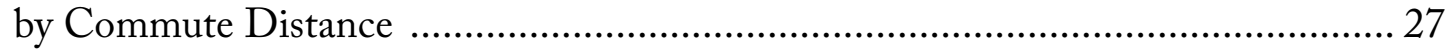

Figure 8. Model Predicted Mean Bike-To-Work Rate of Bike-Lending Participants

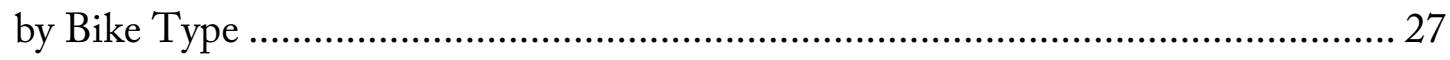

Figure 9. Model Predicted Mean Bike-to-Work Rate of Bike-Lending Participants by Commute Type.

Figure 10. Model Predicted Mean Bike-to-Work Rate of Bike-Lending Participants by Self-Reported Bicycling Skill

Figure 11. Model Predicted Mean Bike-to-Work Rate of Bike-Lending Participants by Use of Strava App Integration

Figure 12. Model Predicted Bike-to-Work Rate of Bike-Lending Participants by Intervention Phase from Trip Logs (Before, During, After)

Figure 13. Model Predicted Bike-to-Work Rate of Bike-Lending Participants by Intervention Phase from Survey ("Before") and Trip Logs ("During", "After")

Figure 14. Model Predicted Average Change in Bike Commute Miles Per Person Per Week Based on the Survey (Before) and Model Predicted Bike Commuting from Trip Logs (During) 
Figure 15. Model Predicted SOV-to-Work Rate of Bike-Lending Participants by Intervention Phase from Survey (Before) and Trip Logs (During) …………………………..... 34

Figure 16. Implied Daily SOV Miles Changes (During - Before) Per Person Based on Model Predicted SOV Rates and Self-Reported Commute Distances.................................. 35

Figure 17. Estimated Program-Level Cumulative Monthly SOV Miles Reduced Based on Model Predicted SOV Rates and Self-Reported Number of Commute Days and

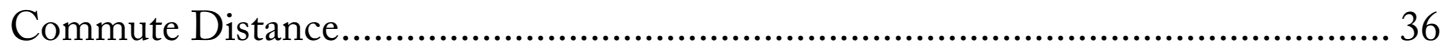




\section{LIST OF TABLES}

Table 1. Commuter Bike on-Ramp Program Timeline and Statistics ................................... 7

Table 2. Bike-Related Amenities, Programs, and Events..................................................... 10

Table 3. Other Travel Services Available for Google Employees............................................ 11

Table 4. Sample Size by Evaluation Phase ........................................................................... 12

Table 5. Zero Inflated Aggregate Binomial Bike- and SOV-to-Work Model Summaries ...... 23

Table 6. Surveyed and Modeled Bike-to-Work Days and Miles............................................. 38 


\section{Executive Summary}

In 2015 Google began a new transportation demand management program designed to increase bike commuting to their two main corporate campuses in Mountain View and Sunnyvale, California. Following a survey of employees, the Google transportation management team determined that bike access and maintenance were strong barriers to bike commuting. Because of this finding, Google designed an e-bike lending program targeting single occupancy vehicle (SOV) commuters to change to bike commuters. Beyond a free e-bike for 6 months, the program included a series of supportive measures to help change travel behavior, including requiring trip reporting and bike commuting for $60 \%$ of commutes, free maintenance and emergency pickup service, among many others. At the end of the 6-month lending period, Google incentivized participants to purchase their own bike to continue their bike commuting. Since 2015, the program has gone through changes that include the introduction of conventional (non-electric) bikes, increases in bike buying incentives, bike buying events, and many others. In addition, this program is just one in a series of programs that help employees choose non-SOV commuting behaviors.

At the beginning of the program, Google received a long wait list of interested employees. By 2017, the waitlist had been cleared and the program was expanded to include all eligible employees. Google tracked compliance with bike commute goals by requiring self-reported commute data. From 2015 through the end of 2019, 2,663 employees participated in the program and provided trip data for a total of 224,415 unique person-commute days.

Through multivariate statistical analysis, results indicate the program led to average increase in bike commuting of approximately 1.7-2.3 days per week, roughly a tripling of prior bike commute rates. After the program, bike rates of participants diminished slightly, but remained much higher than baseline (an increase of 1.3-1.9 days per week). This increase in bike commuting led to 8.410.5 additional bike miles ridden per person per week on average during the program.

Nearly all the increases in bicycle commutes were likely attributed to decreases in SOV commuting. Although only a subset of participants reported all travel modes when commuting (it was not a requirement to report other modes of travel besides bicycling), results suggest that SOV commuting dropped 2.4 days per week on average. This drop exceeds the increase in bike commuting which could be attributed to participants making other changes in their commutes because of the availability of a bike or e-bike, or it could indicate measurement error in reporting of either bike or SOV commute rates. When examining the cumulative effects of the program from mid-2015 through 2019, the results suggest the program reduced approximately 400,000 SOV commute miles. 
Other important findings include:

- Conventional bikes were even more successful than e-bikes. However, e-bikes may still have been necessary given many employees may not have participated had it not been for the availability of an e-bike.

- Multimodal commuters biked more frequently. The sample of multimodal bike-transit or bike-shuttle bus (GBus) commuters was small, but they were more likely to bike compared to bike-only commuters.

- Longer commute distances resulted in less bike commuting. However, even participants with long commutes (> 10 miles) biked more than $40 \%$ on average suggesting that a bike lending program should not limit participation from longer distance commuters.

- Self-reported bicycling skill was positively associated with bike commuting. This result is consistent with the general literature on bicycling.

- Results from participants with app integrated reporting (Strava) suggest either overreporting of bike commutes by non-app participants, or app users biked less than non-app users. More research is needed to determine the validity of each of these potential explanations.

The success of the Google bike lending program should help other employers build their own programs. Although this analysis only includes behavioral modeling, with these results benefit/cost ratios can be calculated to determine the effectiveness of the program compared to alternatives. Like all transportation demand management (TDM) programs, Google's lending program can be improved. In the case of bike lending at Google, the results suggest that (a) permanent lending may be more efficacious than a fixed duration intervention, (b) a wider variety of bike/scooter form factors may be needed to attract more participants, and (c) targeting short SOV commuters could be accompanied with longer SOV commuters if a multimodal option is available. 


\section{Introduction}

Transportation demand management (TDM) is a set of strategies often used by large employers and agencies to maximize employee travel choices and ultimately improve travel reliability. ${ }^{1}$ University campuses are perhaps the best case studies showing the effectiveness of broad TDM programs in the US (McCoy, Andrew, \& Lyons, 2016). TDM strategies not only aim to expand choice but also aim to promote more sustainable travel behavior. Besides walking, nothing is more sustainable than bicycling to work, which is why many TDM programs often have one focus on reducing the barriers to bike commuting.

Barriers to bike commuting are well-documented, with concern for traffic safety and distance (or travel time) topping the list as some of the most important (Dill, 2009; Fowler, Berrigan, \& Pollack, 2017; Heinen, van Wee, \& Maat, 2010; Xing, Handy, \& Mokhtarian, 2010). While improving street design for bicycling is badly needed in most US cities, education, encouragement, and incentive schemes within TDM programs can provide synergistic benefits for increasing bicycling by focusing on reducing other barriers (Litman, 2021).

Bike ownership is a prerequisite for bike commuting (except in locations with one-way bike shares) and has been shown to be strongly correlated with bicycling in general (Handy, Xing, \& Buehler, 2010). Other than the cost burden of purchasing a bike, little is known about the motivations for acquiring a bicycle. In at least one study, some evidence suggests that socio-demographics and travel attitudes influence bike ownership, but the direction of causality is not clear (Ramezani, Hasanzadeh, Rinne, Kajosaari, \& Kyttä, 2021). In many studies of bike commuting, bike ownership is assumed to be jointly made with the decision to commute by bike (i.e., if someone decides to bike commute, they will buy a bike to do it). However, this assumption is particularly problematic if barriers to ownership preclude individuals from considering bike commuting.

\subsection{Bike and E-bike Lending}

E-bike lending has been shown to strongly increase bicycling and decrease driving, more so than conventional bikes (Fitch, 2019). E-bikes allow for greater commute distances because riders can travel at faster speeds with less effort, which is especially true of hill climbing. This reduction in travel time can make e-bicycling more competitive with driving in many environments, and for shorter commutes often makes e-bicycling the fastest door-to-door commute mode. E-bike lending has been examined in a variety of contexts, but perhaps the best available evidence comes from studies in Norway. In a series of studies with brief e-bike lending periods, large increases in bicycling and reductions in driving were found (Fyhri \& Beate Sundfør, 2020; Fyhri \& Fearnley, 2015; Fyhri, Sundfør, \&Weber, 2016). In less robust evaluations, several European studies in the grey literature have demonstrated large increases in bicycling and decreases in driving, the latter of which is particularly apparent for commuting purposes (Fitch, 2019; Haubold, 2016). While the

${ }^{1}$ https://ops.fhwa.dot.gov/plan4ops/trans demand.htm 
evidence is less clear in North America, the few available studies are consistent with the European experience, finding that e-bike owners replace driving for a large percentage of trips (Lamy, 2001; MacArthur, Harpool, Scheppke, \& Cheery, 2018). The potential for e-bicycling to substitute for driving is perhaps greater in North America where driving is a more dominant travel mode. This is especially the case for work commuting.

With the rise of e-bike purchases during the COVID-19 pandemic, e-bikes are no longer an unknown mode of travel in the US. Awareness of e-bikes was likely growing prior to the COVID19 pandemic. For example, after the introduction of an e-bikeshare in Davis, California in 2018, awareness of e-bikes increased from approximately 40 to $80 \%$ of the campus commuting population at the University of California, Davis (Handy \& Fitch, 2020). However, while e-bikes hold promise for increasing bicycling, conventional bicycles are still the dominant form of bike commuting in the US. Conventional bicycles have a few important advantages (e.g., less expensive, less prone to theft, lower maintenance costs), and for those who seek a commute that also satisfies fitness goals, conventional bicycling requires more energy expenditure (although e-bikes still provide important health benefits, see Sundfør \& Fyhri, 2017).

While e-bike and bike lending have been a part of some employer-based and university TDM programs in the US, ${ }^{2}$ there have been few evaluations of their results. In one university bike lending program, bicycling to campus rose but had little effect on car use (Armstrong, 2010). A much smaller lending program (30 bikes, 10-week lending period) at three large employment campuses in Portland, Oregon showed a substantial increase in bike use (MacArthur \& Kobel, 2016). However, that study included mostly existing bike commuters, had no regularly reported trip data (only one mid-program survey), and the sample size for some evaluations were very small (e.g., $\mathrm{n}=37$ for mid-program bicycling use). The lack of robust bike lending evaluations is likely due to the rarity of the programs in the US, but also due to the challenges of evaluating real-world TDM programs. Bike and e-bike lending programs are often one facet of a broad suite of programs to encourage reduction in driving or other related TDM goals.

\subsection{Alternative and Supplemental Strategies}

Some of the barriers to bike commuting may be addressed through TDM strategies such as education and encouragement campaigns. Evidence suggests that policies that combine these types of interventions with infrastructure investments see synergistic effects (Pucher, Dill, \& Handy, 2010). However, the effectiveness of education and encouragement programs at increasing bike commuting is largely unknown and difficult to study because like lending programs, they are often done in tandem with a series of other interventions. One of the most common types of programs is a bike-to-work day which includes a combination of education and encouragement. While

\footnotetext{
${ }^{2}$ https://www.transportation.ucla.edu/getting-to-ucla/bike/graduate-student-bike-rentals, https://salve.edu/bicycle-loan-program, https://www.commuteseattle.com/wp-content/uploads/2021/04/ExpediaGroup-Case-Study.pdf
} 
difficult to evaluate, current evidence suggests behavior change may be limited (Malik, Circella, \& Alemi, 2019; Piatkowski, Bronson, Marshall, \& Krizek, 2015).

Along with encouragement/education campaigns, regular and ongoing monetary incentives are another potential synergistic option. For example, a study of a TDM program to decrease peak car travel to a large college campus showed that monetary incentives can strongly influence travel behavior (Zhu et al., 2014). Not only can incentives be synergistic with mode expansion (e.g., bike lending), but so can disincentives for driving. The high societal cost of providing free parking has been well documented (Shoup, 1997b) and many TDM strategies to reduce single occupancy commuting are thwarted by plentiful parking (Nozick, Borderas, \& Meyburg, 1998). Until parking costs are borne on commuters, TDM strategies are essentially competing against car commuting subsidies in the form of free parking. Given the rising value of urban land making parking extremely costly, successful parking cash out reforms (Shoup, 1997a) are likely to form a strong synergy with bike lending in getting more people to consider bike commuting. However, evaluations of these potential synergies are needed.

\subsection{Case Study: Google Bike Commuter Program (Bike and E-bike lending)}

Google's headquarters, where most of its employees commute daily (prior to the COVID-19 pandemic), are in two suburban office parks: one in Mountain View and the other in Sunnyvale, California. Both office parks were originally designed to prioritize vehicular travel, offering few bike route options. Additionally, these locations lack direct public transit connections, pedestrian walkways, designated bike paths, and a large portion of the land is used for surface parking. As Google continues to grow in Silicon Valley, its ability to be able to continue to develop in the area depends, in part, on TDM solutions to reduce single occupancy vehicle (SOV) commuting and its associated costs (e.g., traffic congestion, parking demand, greenhouse gas emissions, etc.).

Google has set ambitious goals for increasing the sustainability of its workforce's commuting and redesigning the area to improve land use to create more people and place centric campuses that prioritize mixed-use, open space, and green areas rather than parking. Google designed its overarching TDM strategy based on the context of its current commuter needs and travel patterns and based on evidence in the TDM literature to change commuter's habits and behavior. Google's strategy is to offer commuters options and flexibility, recognizing that there isn't one solution that works for everyone, and that commuters' travel needs may change on a day-to-day basis. Google offers a wide range of TDM solutions, including its flagship commuter shuttle program (GBus) that helps over a third of its employees get to and from work every day at no cost to them. Google also offers subsidized public transit passes, free bikes, vanpools and microtransit options, and works with local transportation management associations (TMA) to offer subsidized carpool rides. Although parking is also free and available on a first come, first serve basis, less than $50 \%$ of Google employees commute by single occupancy vehicle (SOV), and bike commuting account for roughly $5-6 \%$ of commutes (Figure 1). 
Figure 1. Google Commuting Mode Split from the 2019 Google Commute Survey

MOUNTAIN VIEW

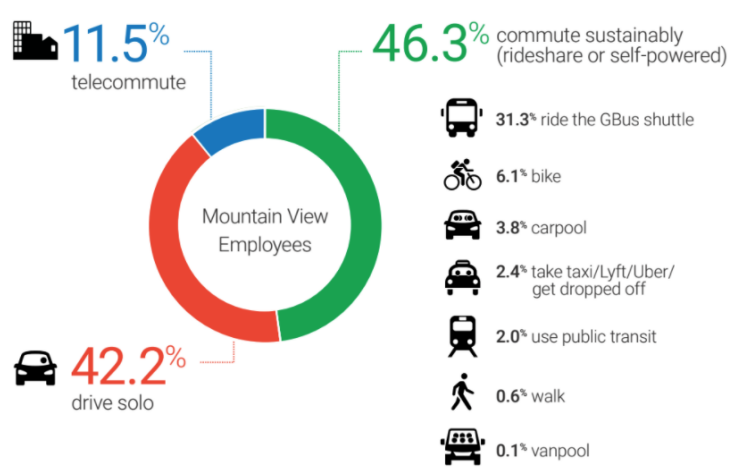

SUNNYVALE

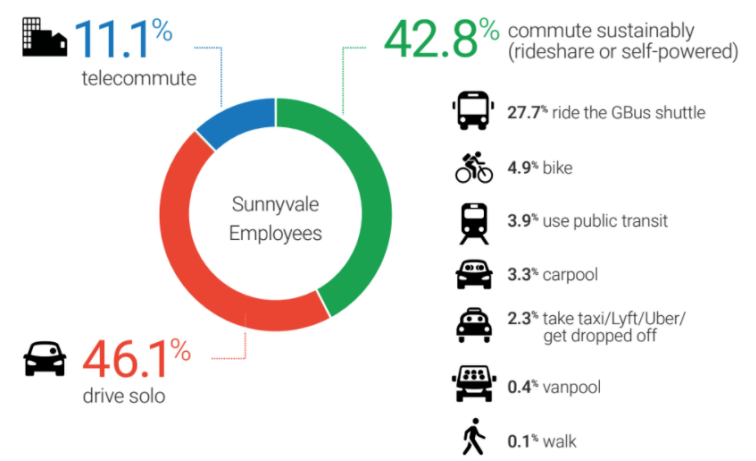

As part of the TDM program, Google sought to increase their near-term bike commuting mode split to $10 \%$, with a long-term moonshot goal to reach $20 \%$. Following an initial survey of the barriers to bicycling to campus, which indicated that bike ownership and worries about maintenance were primary bike commute barriers, Google began a pilot program that loaned highquality electric-assisted bicycles at no cost to interested employees. Included in the offering was free maintenance, helmet, lock, lights, and emergency van pick-up or drop off service. As the pilot grew in popularity and success, it became a full program that required participating employees to commute by bike for $60 \%$ of their commute days and log their commute trips. At the end of the six-month program, participants received a $\$ 300$ subsidy to purchase a bike (or e-bike) in addition to discounts from participating local bike shops during sales events held on campus and at bike shops directly. Over time, the e-bike lending program has grown to include more than 2,600 participants since 2016 and has included many changes to the program, including expanded bike options (non-electric commuter bike) and participation (see Table 1 for details of the program's development). The program continued to evolve throughout the years as program managers received feedback and learned from participants. A six-month period was determined as the minimum required time for a user to build a habit and change behavior as evidence suggests that many habits take a long time to form (Lally, Van Jaarsveld, Potts, Wardle, \& Jane, 2010). Some of the selection criteria and rules for the program included:

- targeted employees who drive as their primary commute mode, as a primary program goal was to reduce driving and parking demand;

- do not have access to a working bicycle;

- live within 20 miles of the office;

- have a safe place to lock the bike at their residence; 
- $\log$ all commute trips daily and bike for $60 \%$ of their commute trips or return the bike if they are not using it;

- agree to program requirements, audits, and responding to surveys; and

- may not share the bike with friends or family members.

Table 1. Commuter Bike on-Ramp Program Timeline and Statistics

YEAR: 2015

\section{MILESTONES}

- Google purchased 500 e-bikes

- piloted by distributing e-bikes to a small group of interested employees

YEAR: 2016

\section{STATS}

$21 \%$ ชิธo

Of Google employees

within 9 miles of work

ride a bike to work

290 过

E-bike Commuters

\section{4,8008}

Global Bike to Work Day

participants (a new record!)

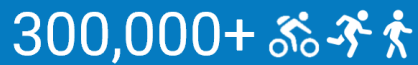

Total global Self-Powered

Commute trips (includes those

who bike, run or walk) in 2016

\section{MILESTONES}

- Pilot became a permanent program

- Allow users to get an e-bike and use it for up to 6 months

- Required $60 \%$ bike commuting to continue bike load usage.

- Targeted solo drivers

- Management of bikes was manual

- Audited compliance every 3 months

- Offered $\$ 300$ for graduates to off-ramp to their own bike through 3 local bike shops

- Piloted a small amount of conventional bikes (100)

RESULTS:

- low compliance

- low graduation rate

- low subsidy claims

- long waiting list (400+) 


\section{STATS \\ $21 \%$ ỡ}

Of Google employees

within 9 miles of work

ride a bike to work

$332 \stackrel{4}{8}$

E-bike Commuters

\section{5,6008}

Global Bike to Work Day

participants (a new recordl)

\section{$360,000+3 \hat{\sigma}_{0}-\xi^{2} \pi$}

Total global Self-Powered

Commute trips (includes those

who bike, run or walk) in 2017

\section{MILESTONES}

- Still targeted solo drivers

- Made conventional bikes a permanent part of the program in May 2017 and reduced waiting list to 0 or with only a 1 week wait

- Changed audit from quarterly months to monthly

RESULTS:

- Frequent check-ins improved compliance and graduation rates, but subsidy claims are still low

- Improved tracking of both bikes and users, but still a lot of manual work

- Improved customer service by adding staffing support to answer questions and distribute more bikes to reduce waitlist

\section{YEAR: 2018}

\section{STATS}

\section{$400+\frac{*}{86}$}

E-bikes

\section{$500+\infty$}

commuter bikes

\section{$1,220+$}

Google employees

joined the program in 2018

\section{4\% ชิ่}

Said they would continue

to bike to work more than three times a week

\section{MILESTONES}

- Seeing the lack of engagement with the subsidy, started to bring local bike shops on-site to sell directly to employees. Sales event offered users special discounts and subsidies for those who are eligible. Events were attended by over 500 people

- Improved compliance rate, but still hovered around 65\%

- Improved graduation rate and improved subsidy claims as a result of the on-site sales events 


\section{STATS}

\section{$1,420,000$ oิ̀o}

Miles commuted on bikes

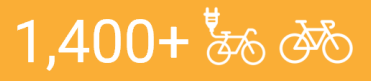

Commuter and e-bikes in fleet

$1,500+$ inimi

Employees enrolled in

On-Ramp Program in 2019

$3,000+5$

Regular bike commuters

\section{MILESTONES}

- Implemented Salesforce to help track bikes and participants (Salesforce is now used through the whole process from intake to assignment of bikes)

- Improved audit and calculation of compliance

- Changed subsidy from $\$ 300$ to $\$ 500$ for e-bike purchases due to low e-bike conversion

- Increased Bike Sales to 3 times a year

YEAR: 2020

\section{STATS}

$2,400+\pi$

visitor, commuter and e-bikes in fleet

\section{$500+$ ๙ॅ॰}

bikes loaned out

from Jan-Feb 2020

\section{$1,000+\frac{3}{30}$}

bikes loaned out

from Jun-Dec 2020

\section{MILESTONES}

- Program paused due to pandemic and mandatory WFH orders

- Transitioned to help employees bike while at home through "Biking at Home" program by removing compliance and offering bikes to anyone interested in biking

- Provided bikes and repair services to employees interested in bicycling in hopes that they'll create a biking habit and will continue to bike commute to work once they return to work 


\section{Table 2. Bike-Related Amenities, Programs, and Events}

\section{Bike Amenity}

- Indoor and outdoor bike parking at every office building, e-bike charging available at indoor locations

- Bike Hubs provides on-site customer services and offers daily free bike rentals

- On-site bike repair services at multiple locations

- Showers, changing rooms, and on-site laundry at some offices

- Lockers for short and long-term use

- Helmets

- GBus and emergency ride home vehicles equipped with bike racks

\section{Bike Incentives}

- Bike maintenance and advocacy workshops

- Learn how to ride bike classes

- Subsidized safety gear sales event

- Discounts at local bike shops with major bike brands

- Biking incentive programs

- Bike fairs to test bikes and e-bikes

- Bike to Work Day celebrations

- Group rides to work

- Mid-day group rides

- Presentations to employees about Google's efforts to improve their commute

- New employee orientation includes custom commute options

\section{Bike Sale Events}

To aid employees in making the transition from the Commuter Bike Program to owning a bike, Google invites select local bike shops to Google campuses to sell bikes three times a year (560 bikes sold in 2018 through this event).

\section{Infrastructure}

Google continues to pursue infrastructure projects that make the area a safer, more pleasant place to bike

Some examples include the resurfacing of the Bay Trail , and updating connections between offices including building buffered bike lanes, bike boulevards, bike boxes, and more. 
Table 3. Other Travel Services Available for Google Employees

COMMUTE OPTIONS
- Free commuter shuttles
- Public transit subsidies
- Free vanpool
- Free parking
- Free microtransit

\section{MID-DAY OPTIONS}

- Intercampus shuttles

- On-demand intercampus shared rides

- Hourly car rental

- Bikeshare 


\section{Methodology}

\subsection{Data Collection}

In cooperation with Google, we synthesized anonymized survey and trip data collected as a part of the program operations and compliance. We summarized the trip data at the person-level in three phases: before program participation (Before), during program participation (During), and after program participation (After) (See Table 4). Trip data was collected by Google in one of two ways: (1) self-reported daily commute data (reported every month) through an online form; or (2) use of an integrated smartphone app (Strava). Participants who chose to report trips through Strava had each commute distance measured by the Strava app, otherwise participants' commute distance was self-reported at the beginning of the program and assumed to be constant through the life of the program unless reported to have changed by the participant. We included all program participants who recorded trip data during the program and retained trip data within 1 year prior to and any time during and after graduation from the program. Trip data was only required for the during phase (while employees were loaned a bike) which is why the unique person-commute days for the before and after phases are much lower (Table 4).

Table 4. Sample Size by Evaluation Phase

\begin{tabular}{|c|c|c|c|}
\hline Program Phase & Unique Months & Unique Persons & $\begin{array}{c}\text { Unique Person- } \\
\text { Commute Days }\end{array}$ \\
\hline before & 66 & 1,707 & 73,910 \\
\hline during & 55 & 2,663 & 224,415 \\
\hline after & 43 & 1,033 & 120,140 \\
\hline
\end{tabular}

To administer the program, Google collected data from participants in two surveys, an application survey (before program enrollment) and an exit survey (after program graduation). Because the program went through many changes since it launched in 2015 through to the end of this study period (December 2019), the survey data from different date ranges required some synthesis and organization. In total, application survey data was stored in six spreadsheets, and we merged questions with slight changes in wording where possible. Most application surveys included key variables in the modeling and analyses. The primary variables in the application data are anonymized person id, application date, primary commute mode, weekly frequency for each mode, commute distance, and commute time. Nearly all participants reported all these variables in our study sample, but the same is not true of the exit survey. Only $34 \%$ of study participants completed the exit survey. This is likely because the participants already received their bike subsidy and 
graduated from the program prior to being recruited to take the exit survey. For this reason, we only use exit survey data for ancillary analyses, not for the primary program evaluation. The exit survey asked many questions about the program and collected comparative commute data, such as primary mode, commute time, and bike frequency before and during the program.

In addition to survey data, data on when participants received a bike and when they graduated from the program were used to help define person-specific study phases (before, during, and after) described below in the data synthesis process.

\subsection{Data Cleaning and Synthesis}

The raw data was cleaned and organized into person-level data and trip-level data for the primary analyses. We synthesized the raw trip data into commute data by examining trips taken within normal commute time windows to Google's two campuses. Because compliance was conducted at the commute level (to and from work) we divided trips into morning and afternoon commutes by time of day. For our analysis, trips during the mid-day and evening periods were ignored. We explored the differences between morning and afternoon commute mode patterns and found them to be nearly identical (only rarely did participants commuting by different modes within a single day). Because of this pattern, we chose to focus on morning commutes only for evaluation. In some cases, participants traveled by multiple modes (e.g., biked and took GBus to work). We wrote an algorithm based on timestamps of different modes to determine if people were making multimodal morning commutes and classified them as such. We also explored differences in bike commuting based on self-reported vs. app integrated trip reporting. We inferred the use of an integrated app by the number of digits recorded for the trip distance, which likely indicated whether the trip was recorded manually or using an app.

We determined the person-specific program phase (before, during, and after) based on the bike issue and return dates, and graduation date. ${ }^{3}$ Because of missing data for some bike trip logs and graduation, we had four scenarios for determining program endpoints (all participants had bike issue dates that determined program start point): (1) if the participant had a bike return date, it was used; (2) if the participant had a missing return date, but had graduation data, the graduation date was used as the endpoint; (3) if return and graduate date were missing, but the exit survey was available, the eligible subsidy date was used as the endpoint; and (4) if none of the above dates were available, the endpoint was assumed to be six months (the normal length of the lending period) after they were issued a bike. All participants recorded trips during the program, but only some participants recorded trips before and after the program (Table 1 ). The reasons for recording trips before and after the program were likely for concurrent TDM programs such as obtaining other commuter benefits, ${ }^{4}$ but because we do not know the motivation for each person, we did not

\footnotetext{
${ }^{3}$ Graduation occurred when a participant successfully completed a 6-month period of riding $60 \%$ of the time or more. Some participants graduated early to sync with on-campus bike sale events.

${ }^{4}$ The commuter benefits program at Google incentivizes employees who bike to work by giving them rewards (e.g., bicycling gear) in exchange for recording bike trip data.
} 
speculate on other policy variables in our analysis. We explore the potential bias in the before and after data in section 2.5 Limitations.

Because of the large amount of the data (see Table 1) and the focus of our analysis on a general evaluation of the program, we aggregated daily commute data for modeling. First, we aggregated workdays at the month level (subtracting holidays, out-of-office, and telework) to estimate physical commute days per month per participant. Although we did not include weather event data, by analyzing data at the month level (e.g., March 2017), some level of seasonality and specific weather events were adjusted for in our analysis (e.g., a historically rainy May 2018). The month acts as a surrogate for variation caused by unmeasured time-varying predictors. The process of cleaning and synthesizing data is summarized in Figure 2 below. We also removed trip data that occurred more than one year prior to the start of the bike lending period. We did this because in our summary statistics we noticed many participants had biked to work many years before the program, but not within the immediately preceding year. This decision makes our evaluation of behavior change from trip data based on the most recent prior year of travel.

Figure 2. Data Cleaning and Synthesis Process

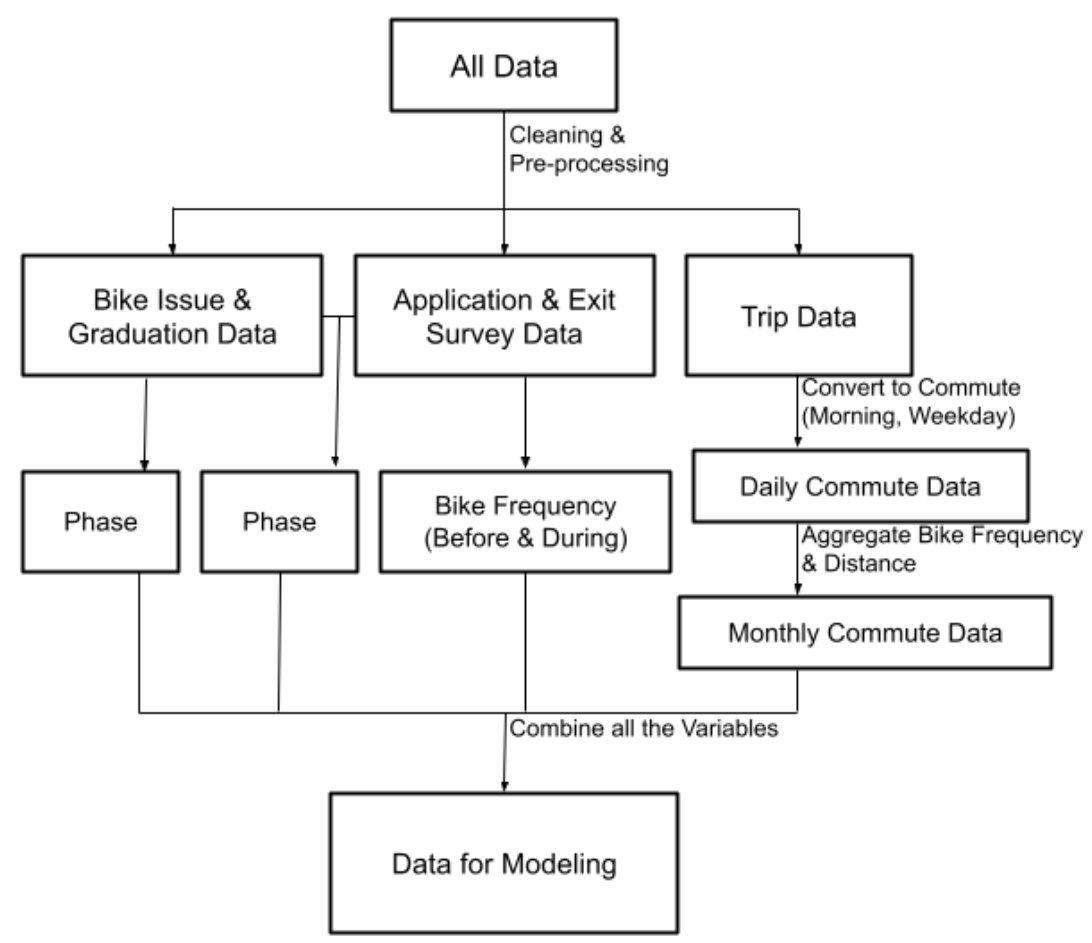

\subsection{Evaluative Framework}

We focus on the following bicycling and SOV outcome variables to evaluate the program: average bike commute rate, bike commute distance, and SOV commute distance. Bike commute rate is the primary focus of program compliance and most closely matches the goals of the program. We 
consider bike commute distance as a secondary outcome of interest because the physical activity benefits accrued from bike commuting are more closely relate to total bike distance than to bike commute frequency. We evaluated SOV commute distance to better understand how increases in bicycling were impacting SOV commuting. Because of the limitations with the commute data in the before and after periods (see section 2.5 Limitations below), we consider the bike commute effect of the program in two ways: (1) by modelling predicted differences between phases based on reported trip data; and (2) by comparing the before survey data with the model predicted during and after rates extracted from trip data. Each evaluation has potential error and bias, and the "true" program effect is likely to be somewhere in-between these estimates. For SOV commutes, we only considered the before survey data with the model predicted during data as the before and after SOV commute data was too limited.

\subsection{Effect Analysis}

We evaluated the program by first reporting bivariate statistics of the outcome variables with key control (distance) and program variables (phase). These statistics help indicate the expected program effect and ground the subsequent analyses that are more complex. After the bivariate statistics, to evaluate the outcomes, we use multivariable statistical modeling that considers the complexity of the data as it was generated, the unique variation by each participant, and adjustments to the estimated program effects based on key variables such as bike-type and commute distance. Specifically, we estimate multilevel (by person and by year-month) zeroinflated aggregated binomial regression models. Conceptually the binomial models estimate the likelihood of a participant bike (or SOV) commuting on a given day in each year-month that they reported commuting. Because the data has more zero bike (or SOV) days than would be expected from a binomial process, we included a parameter to inflate the zeros to better ensure our model estimates are not upward biased. We suspect the added number of zero days is due to people reporting no bike commutes for days in which they never commuted (e.g., non-reported vacation or work-from-home), but the extra zeros could have arisen from other unknown reasons.

To estimate the distance outcome variables, we simply multiply the reported commute distance by the model estimated commute frequencies and multiply by two (assuming the same commute mode to and from work). For app registered commutes, the distance summarization method was based on the estimated trip speed and time difference between trips. If the time difference between trips was less than 20 minutes or the average trip speed was greater than $20 \mathrm{mph}$, we assumed the trips were duplicates (somewhat common for app-connected trip data) and we therefore averaged the trip distance, otherwise we summed the miles. This approach for estimating bicycling miles from the program is rudimentary and does not consider the variety of additional bicycling that occurs from the program (e.g., non-commute bicycling). It should be a conservative estimate of added bike miles (and thus physical activity) caused by the program. 
We also estimated the effect of the program on SOV commuting and on reducing SOV commute miles. For this analysis, we subset the data since SOV commute reporting was relatively rare from participants as it was not required. We used the following constraints to subset the data:

1) a participant must have at least 8 weeks of commute data that includes all travel modes during the program; and

2) the 8 or more weeks with all commute modes must be $10 \%$ or more of a participant's total reported weeks during the program.

These constraints helped to ensure that we only considered data where SOV commutes are legitimately being reported by participants.

\subsection{Limitations}

The primary limitations for evaluating this program derive from the lack of repeated and objective data on travel before and after the program. This is a problem that plagues most TDM programs because evaluation of program effectiveness is often a lower priority than implementation, and because the requirements for conducting high quality evaluations can (and likely do) influence the program and lead to inequities in implementation. For example, had Google required the reporting of a month of travel data prior to the bike lending period, many participants may have never begun the program. In general, TDM programs want to capture the excitement for a new program and reduce barriers to entry when launching. As such, delaying the direct benefits of a new program with a lengthy data collection may reduce the effectiveness of such a program.

In this study, the before and after trip data are likely biased for several reasons. The before trip data is likely biased to those already bicycling to work ( $76 \%$ of the participants that report before data report at least one bike trip before the program, while $78 \%$ of participants report never bicycling in the before survey), a sub-sample that is not the primary target for the program. The after-phase trip data may also be similarly biased ( $97 \%$ of the participants that report after data report bicycling, while only $74 \%$ of participants in the exit survey think they will continue to bike). However, the exit survey was completed by so few participants ( 710 out of 2712 ), that the survey responses are likely an unreliable estimate of the entire program. This is partly because the exit survey was initially only designed for those who did not graduate but was later adopted for all participants. Even though the responses are few, they do allow for validation of trip reporting at the person-level (see Section 3.2). Even trip data collected during the program has its limitations. Many person-weeks had completely missing data and we were not able to determine if this was because the participant forgot to submit data or didn't travel to work that week. We ignored these weeks in our analysis which may have led to unknown biases.

We used the before survey data on commute behavior, but that data is also likely biased (see results). It is likely downward biased from people underreported bicycling behavior prior to the 
program to get a bike. We assumed that the before trip data was more accurate at the person-level (not population) and calculated two versions of the program effects based on survey or modeled trip data baselines (see Section 2.4).

During the bike/e-bike lending program, the commute rewards program was also running, and many people chose to participate in both. We attempted to account for the combined programs versus unique programs, but because it was not feasible to obtain dates for when people were trying to accumulate commute rewards points (we only knew who had ever redeemed a reward during the entire study period), it made differentiating the effects of the lending program and the rewards program impossible. Because the rewards program was available to all participants during this study, we assume that the effects we observed for the lending program are in fact the effects of the combined programs.

Finally, several important person-level variables are absent from this dataset. Most notably, Google does not collect information about socio-demographics, household structure, or any other travel that is not commuting. These and many other variables could have important effects on bike commuting that are not accounted for in this analysis which increases the uncertainty in our evaluation. 


\section{Descriptive Analysis}

\subsection{Bike Commute Summaries}

The number of participants for each person-averaged weekly morning bike commute is plotted in Figure 3 for each project phase. The trends in weekly bicycling suggest the program greatly increased bicycling and this increase was sustained after the program. Only the "before" panel shows many commuters with zero or near zero weekly bike commute averages, while the "during" phase shows the most bike commuting, and the "after" phase maintains much of the same distribution as the "during" data. As other factors could have caused these differences, we examine the results through a multivariable model for further evaluation (Section 4).

Figure 3. Histograms of Person-Level Average Weekly Morning Bike Commutes by Project Phase

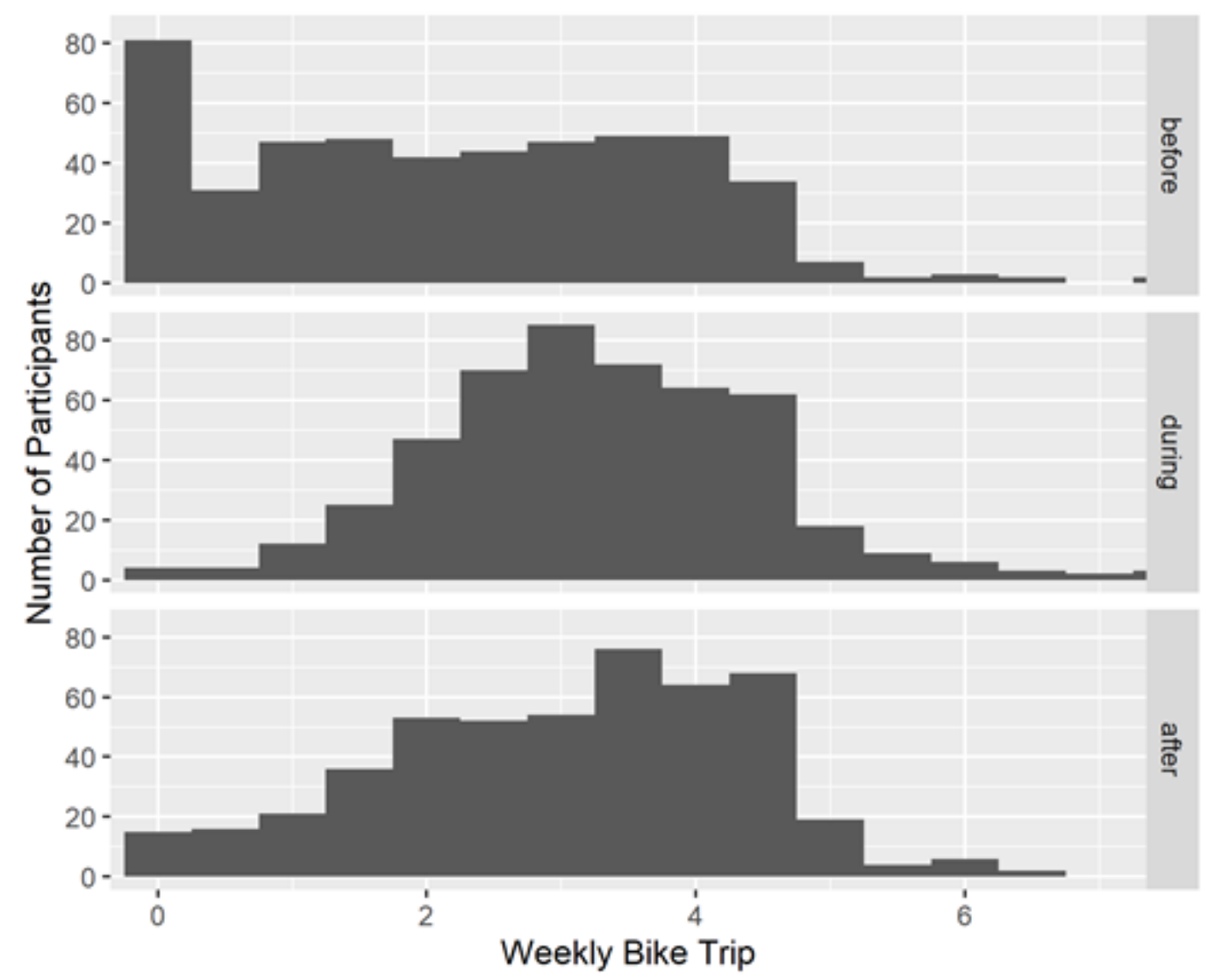

While the program had a large initial waitlist and first only sought participants who car commuted within reasonable bike distances, the program eventually fulfilled the entire waitlist and included many participants who already bike commuted at least some days a week in hopes they would bike more frequently after joining the program. Figure 4 shows the distributions of bike commutes by project phase like Figure 3, but also by self-reported general weekly bike commuting at the time 
participants signed up for the program ("before" data from the program application). While Figure 4 suggests the participants who were bicycling $3+$ days per week before the program biked the most during the program, the group that never biked before ended up with the largest bicycling increases, biking between 3 and 4 days a week in the "during" and "after" phases of the program (just like the $3+$ before bike commuters). The last panel of plots in Figure 4 shows the participants who didn't report their prior bicycling. While they are a substantial fraction of the participants, they biked at slightly lower rates on average, similar to the participants who reported 1-2 days of "before" bicycling. Like in Figure 3, the results in Figure 4 do not account for factors other than the program itself. However, the basic statistics suggest the greatest program gains are from the participants who never bike commuted prior to the program. Those that already biked $3+$ times per week saw very little boost to their bike commuting on average. Note, the grouping of $3+$ timers per week was of our design. Participants could report 4 or 5 times per week.

Figure 4. Histograms of Person-Level Average Weekly Morning Bike Commutes by Project Phase (Row Panels) and by Self-Reported Bike Commute Frequency (Column Panels) Before Participation (dashed vertical line is the group mean)

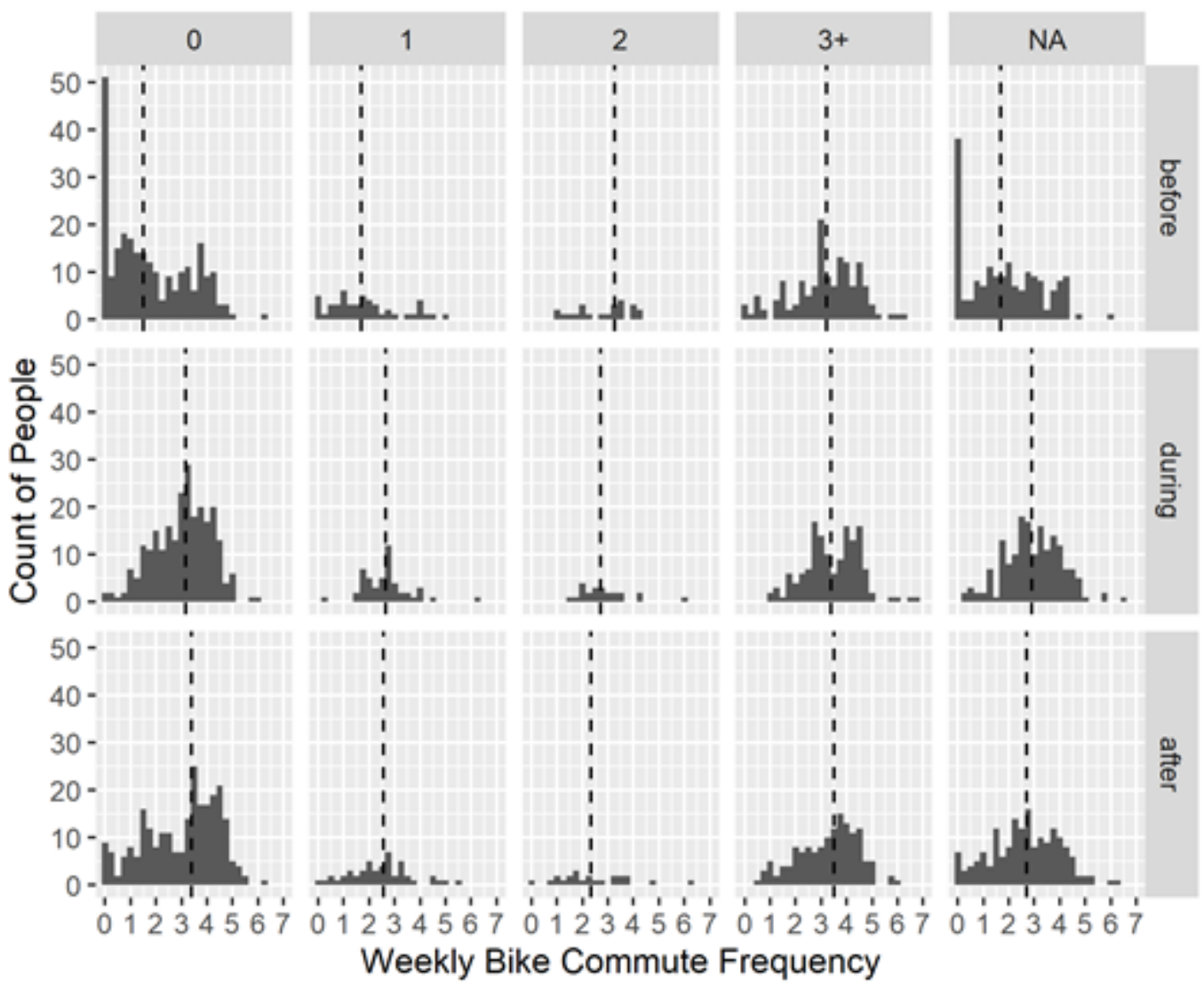

Bike commuting by program participants was predominantly done as a direct single mode commute. Less than $10 \%$ of participants ever made multimodal commutes, and multimodal commutes were a very small share of total recorded commutes (1\%). The small share of multimodal 
commutes was primarily because the program disallowed the e-bikes on GBus and transit because of their weight. Only 18 of the 2712 participants made $80 \%$ or more of their bike commutes as multimodal trips. This is important to consider because even though the behavior is rare, those people who did make multimodal commutes with their conventional bikes, bike commuted more often (see Section 4.1 below).

\subsection{Data Reliability}

All the data summarized and modeled in this report is self-reported. While a small fraction of participants chose to link a smartphone app (Strava) to their account to automatically record bike trips, the vast majority manually reported commute diaries monthly. Manual commute diaries are subject to unknown error, and since participants were required to bike $60 \%$ of their time to be in program compliance, participants may have over reported their bicycling during the program. However, a comparison between the people who used the smartphone app integration vs. those who manually reported their trips showed very similar results, suggesting that the manual reporting bias may be small. Additionally, many participants self-reported bicycling less than $60 \%$, even knowing the program requirement, another indicator of potentially small bias in the bike commute data. This may be in part explained by the fact that Google TDM managers, while threatening to revoke bikes for lack of commuting compliance, never did so during the program. In fact, while participants were expected to commute $60 \%$ of the time with their bike, non-compliance was only acted upon when the biking rate dropped below $50 \%$.

We performed one check on the reported bike commute data during the program by comparing it to the self-reported general bike commuting in the exit survey. We found that the exit survey participants reported more bicycling than they did with their trip data during the program (by about $44 \%$ on average). However, the sample size was very small for the exit survey (since it was voluntary) and so we are less sure this average generalizes to the entire participant population. Because the exit survey suggested the bike commute data during the program was under reported; or perhaps that the exit survey was over-reporting the actual bike commuting, we chose not to make any adjustments to the trip data.

Because of these reasons, we made no bias adjustments to the bike commute data for the "during" and "after" phases of the program. However, the self-reported bike commute data before the program was subject to different biases. The "before" bike data may have been deflated by potential participants who may have thought that they wouldn't receive a bike or e-bike if the TDM managers knew they already bike commuted semi-regularly. In fact, for the small subset of participants who logged commute trips before the program (within one year from the start) they self-reported much fewer bike commutes on the application. The error is primarily due to the large number of participants reporting never biking to work but who with trip data reported bike trips for other reasons. The reported general bike commuting before the program is downward biased by $19 \%$ on average, or the trip data is upward biased by the same amount, or the true bias for each is somewhere in-between. 
Finally, we examined the accuracy of self-reported commute distance by comparing to Strava estimated commute trips for the select participants who used Strava. Figure 5 shows that the selfreported commute distance accurately represents mean commutes, but considerable variation in commute distance (perhaps from trip-chaining or detours for exercise) is not accounted for when only reporting "regular commute distance". Importantly, the self-reported commute distance was done based on driving for most participants, so the comparison between the self-reported and the Strava calculated distances is not entirely apples to apples since bike routes often deviate from car routes substantially.

Figure 5. Self-Reported Vs. Strava Measured Commute Distance

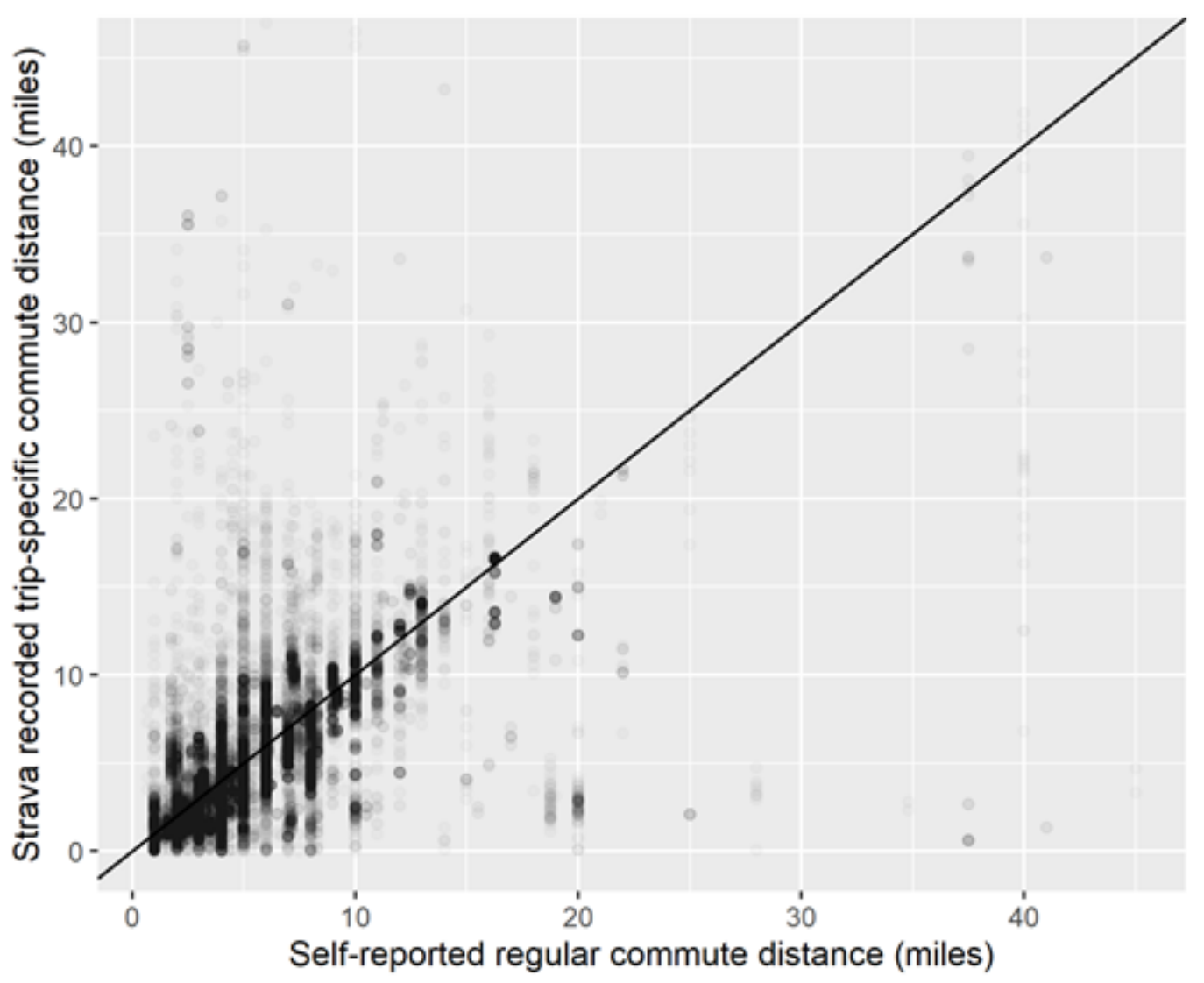




\section{Effect Analysis}

\subsection{Model Results and Influential Variables}

The model results (as logit coefficients) are presented in Table 4. The large coefficients for the "during" and "after" phases suggest that the program substantially increased bicycling to work for program participants. However, because of the potential biases of the data (as discussed in Section 3.2) and the complexity of two and three-way interaction effects, we provide a more complete analysis of the overall program effects in Section 4.2 below. Table 4 does help to understand person and year-month level variability in bicycling to work by comparing the standard deviation and correlation parameters. Person-level variation in biking to work is much larger (more than 3 times) compared to monthly-level variation. We assume monthly-level variation is determined largely by weather patterns and seasonal vacationing (see Figure 6). Also, person-level variation in average bicycling to work is about the same as the person-level variation in the effect of the program on bicycling to work. This suggests that it is not a small subset of highly motivated participants that are making the program successful, but instead that the program works for a wide variety of participants. Finally, program participants who did not bike much before the program saw much larger effects of the program since the correlations between "before" and "during" as well as "before" and "after" were strongly negative. 
Table 5. Zero Inflated Aggregate Binomial Bike- and SOV-to-Work Model Summaries

\begin{tabular}{|c|c|c|c|c|}
\hline \multirow[t]{2}{*}{ Variables } & \multicolumn{2}{|c|}{ Bike Commute Model } & \multicolumn{2}{|c|}{ SOV commute Model } \\
\hline & Mean & Std. Dev. & Mean & Std. Dev. \\
\hline Phase: Before (Intercept) & -0.668 & 0.076 & -6.363 & 0.514 \\
\hline Phase: During & 1.921 & 0.056 & 2.918 & 0.482 \\
\hline Phase: After & 1.511 & 0.067 & 2.004 & 0.509 \\
\hline Log(Commute Distance) & -0.299 & 0.031 & 0.331 & 0.124 \\
\hline $\begin{array}{l}\text { Phase: During } \times \text { Started Before March } \\
2016\end{array}$ & -0.172 & 0.097 & -0.043 & 0.304 \\
\hline Phase: After $\times$ Started Before March 2016 & -0.513 & 0.165 & 0.045 & 0.579 \\
\hline Phase: During $\times$ Bike Type: E-bike & -0.235 & 0.044 & 0.647 & 0.163 \\
\hline Phase: After $\times$ Bike Type: E-bike & -0.246 & 0.075 & 0.876 & 0.321 \\
\hline Phase: During $\times$ Strava use once or more & 0.092 & 0.043 & -0.463 & 0.140 \\
\hline Phase: During $\times$ Skill: Intermediate & -0.099 & 0.037 & 0.242 & 0.122 \\
\hline Phase: During $\times$ Skill: Beginner & -0.207 & 0.069 & 0.385 & 0.221 \\
\hline $\begin{array}{l}\text { Phase: During } \times \text { Multimodal commute } \\
\text { once or more }\end{array}$ & 0.146 & 0.046 & -0.062 & 0.227 \\
\hline
\end{tabular}




\begin{tabular}{|c|c|c|c|c|}
\hline \multirow[t]{2}{*}{ Variables } & \multicolumn{2}{|c|}{ Bike Commute Model } & \multicolumn{2}{|c|}{ SOV commute Model } \\
\hline & Mean & Std. Dev. & Mean & Std. Dev. \\
\hline $\begin{array}{l}\text { Phase: During } \times \text { Strava use once or more } \times \\
\text { Percent Strava reported commute }\end{array}$ & -0.869 & 0.088 & 0.540 & 0.289 \\
\hline $\begin{array}{l}\text { Phase: } \text { During } \times \text { Multimodal commute } \\
\text { once or more } \times \text { Percent Multimodal } \\
\text { commutes }\end{array}$ & 0.392 & 0.182 & 0.296 & 1.434 \\
\hline Std. Dev. (Phase: Before) [person] & 1.651 & 0.043 & 4.799 & 0.446 \\
\hline Std. Dev. (Phase: During) [person] & 1.500 & 0.041 & 3.760 & 0.404 \\
\hline Std. Dev. (Phase: After) [person] & 1.711 & 0.052 & 3.051 & 0.421 \\
\hline $\begin{array}{l}\text { Cor. (Phase: Before, Phase: During) } \\
\text { [person] }\end{array}$ & -0.804 & 0.012 & -0.909 & 0.023 \\
\hline Cor. (Phase: Before, Phase: After) [person] & -0.670 & 0.021 & -0.651 & 0.093 \\
\hline Cor. (Phase: During, Phase: After) [person] & 0.823 & 0.014 & 0.815 & 0.053 \\
\hline Std. Dev. (Intercept) [year-month] & 0.291 & 0.028 & 0.448 & 0.060 \\
\hline Zero Inflation & 0.044 & 0.002 & 0.150 & 0.008 \\
\hline Total Participants & 2,712 & & 893 & \\
\hline Total Person-Months & 26,186 & & 8,153 & \\
\hline Total Person-Commute Days & 388,402 & & 99,498 & \\
\hline
\end{tabular}


Because of the complexity of the model, direct inferences from the model parameters in Table 4 are challenging. In the following plots, we examine some of the effects of important variables through predictive plots (simulating predictions from our models). The simulations have the benefit of showing the effect of variables on a meaningful scale (e.g., the bike-to-work rate). However, they are all conditional on counterfactuals (holding all the other variables at their mean or reference category).

Figure 6 shows the person-level month to month variation in bicycling to work. Each line represents the predicted mean of a single person during their program participation. Winter season dips are almost always apparent, but one dip in the summer of 2018 is more difficult to explain. We examined records of smoke due to wildfires but could not find anything that might indicate such a steep drop in bicycling (trend appears in the raw data as well as the model predictions). The relatively few predictions in the early years are due to the slow start of the program, but by 2019 the program had been expanded considerably and the trends in bicycling became more stable over time. Just like Table 4 indicated, Figure 6 shows that the person-level variation (the range of lines from top to bottom) is much larger than any predicted monthly-level change for a given person. Although program compliance was set at 50-60\%, many participants didn't achieve that level of bicycling on average. However, nearly all participants biked to work six days a month or more (>=30\%).

While winter months were a strong determinant of reduced bike-commuting, commute distance was even stronger (Figure 7). Only participants living within about 2.5 miles from work were on average bicycling $60 \%$ of the time during the program. At the same time, those with much longer commutes (up to 12.5 miles) still bike commuted a considerable amount on average (above 50\%). This finding suggests that bike and e-bike lending can work to encourage bike commuting at longer distances than are normally seen as "bikeable".

The difference between participants who chose a conventional bike instead of an e-bike was a surprise finding (Figure 8). On average, the conventional bike participants biked to work at slightly greater rates compared to their e-bike counterparts without considering commute distance. When we examined if the difference in bike commuting by bike type varied by commute distance, we again were surprised to find no substantial change in the use of e-bikes. Instead, after considering commute distance, the use of conventional and electric bikes was essentially equivalent suggesting that e-bikes did not spur a lot of long-distance commuting (results not shown). While these results suggest that conventional bikes may be a better choice for a lending program (especially considering their cost differences), we caution against assuming that conventional bikes alone could have achieved the same program demand that a paired conventional and electric bike lending program did. E-bikes have a large advantage for longer commutes and have been shown in many studies to increase the use of bikes for transportation and as a car replacement (Fyhri \& Fearnley, 2015; MacArthur, Dill, \& Person, 2014). Many of the e-bike participants may never have participated had only a conventional bike been available. Without a controlled experiment where 
participants randomly get a conventional or electric bike (something no TDM program could feasibly tolerate), we cannot fully understand the effects of the different bike types.

Figure 6. Model Predicted Person-Level Bike-to-Work Rate During the Program

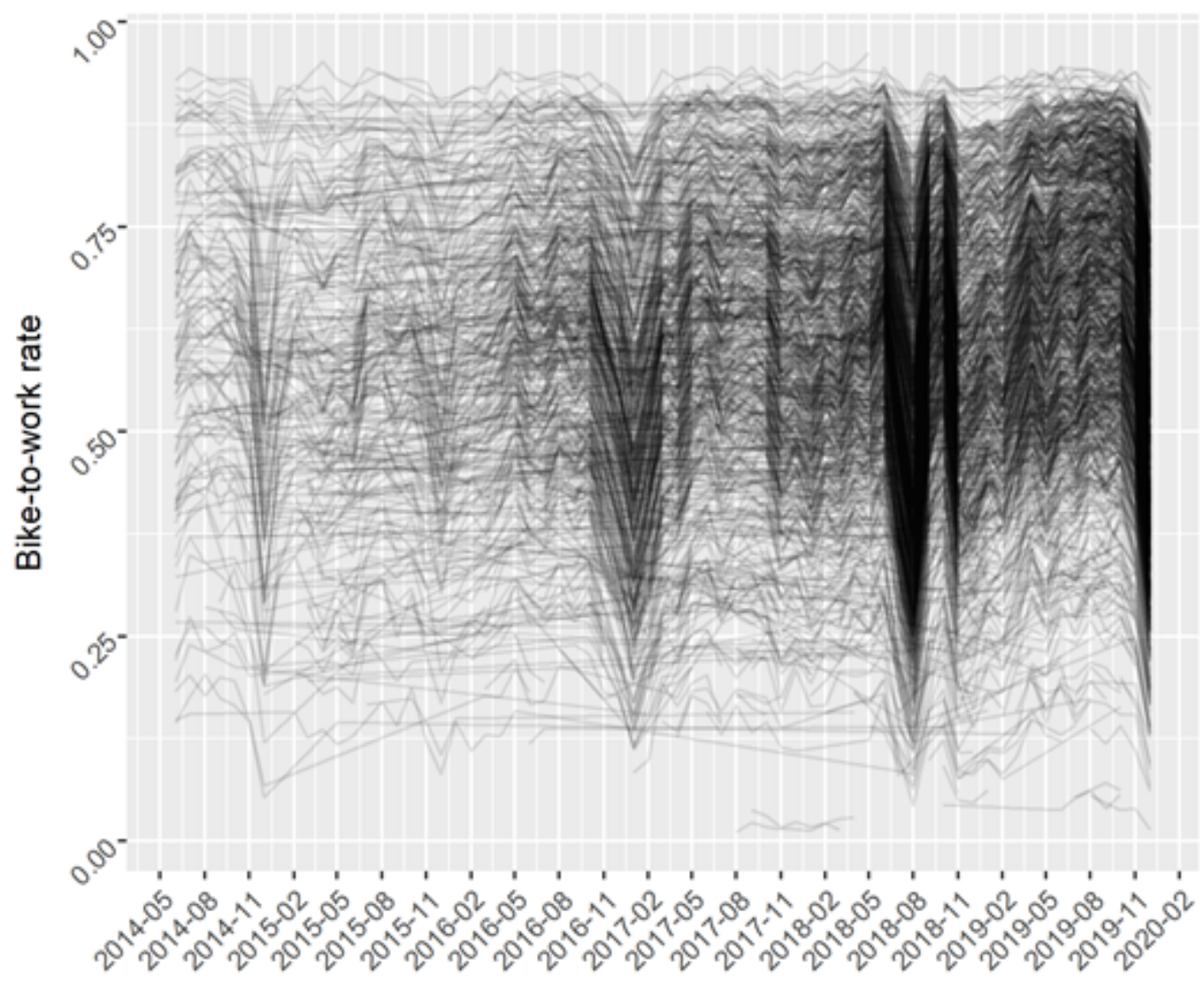


Figure 7. Model Predicted Mean Bike-to-Work Rate of Bike-Lending Participants by Commute Distance

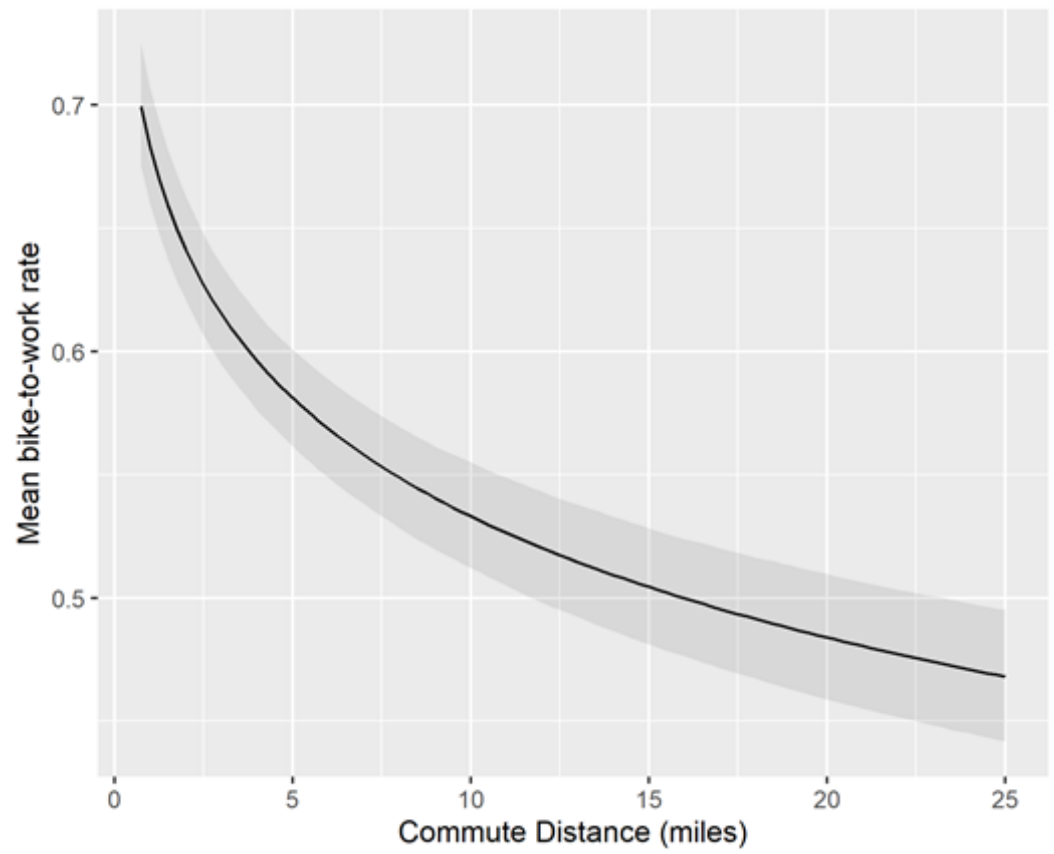

Figure 8. Model Predicted Mean Bike-to-Work Rate of Bike-Lending Participants by Bike Type

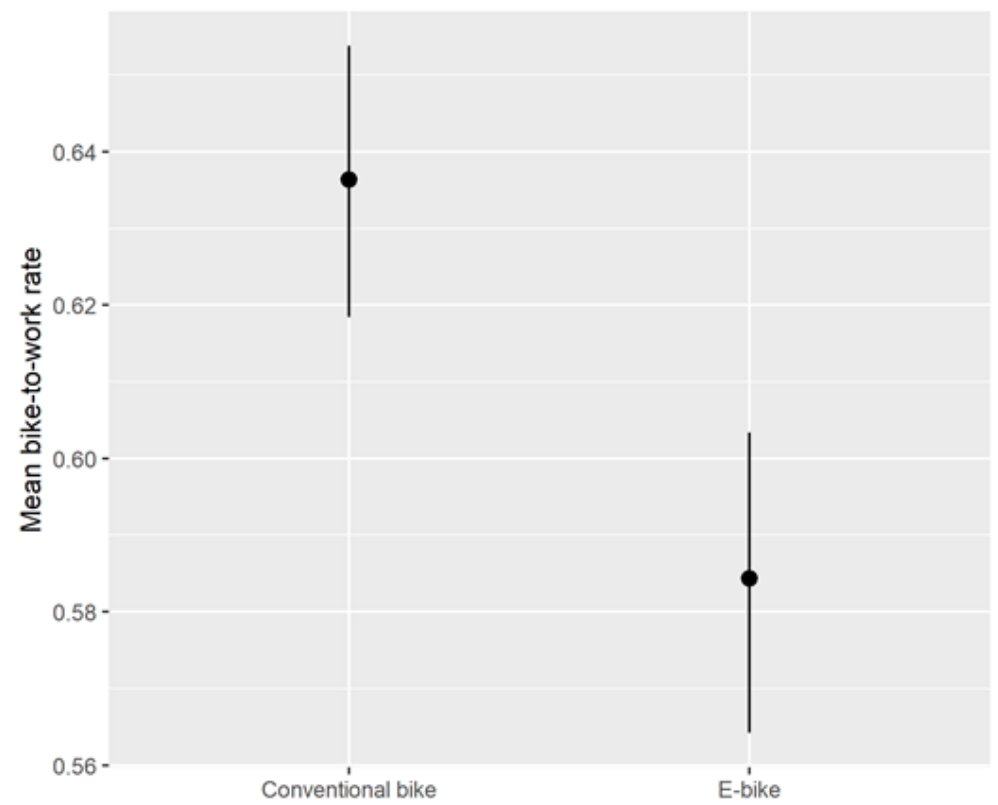

Another somewhat surprising finding was the slight increase in bicycling during the program for participants who made multimodal journeys to work (Figure 9). We considered any bike journey to work multimodal if it included both bike and either a form of public transit or GBus (we didn't 
differentiate between GBus and public transit). However, the mean effect of making a multimodal commute with the bike compared to a direct bike commute is quite small as people rarely made multimodal commutes, it is only when people regularly make multimodal commute that we observe a strong increase in bike commuting (Figure 9). Only conventional bike recipients were allowed to make multimodal commutes, so the multimodal effect is likely only applicable for conventional bicyclists.

Less surprising was the finding that more skilled bicyclists bike commuted at greater rates during the program (Figure 10). However, the fact that self-identified beginner bicyclists biked on average nearly $60 \%$ of the time suggests that bike lending programs do not have to only focus on advanced riders but can be used to target commuters with a wide range of skill levels. It is not clear from this analysis what the bicycling environments were like for each commuter but considering that the surrounding routes to Google's two campuses have a lot to be desired for providing safe routes to work, ${ }^{5}$ the successful bike commuting for beginner bicyclists is even more noteworthy.

Finally, the model predicted effect of integrating Strava rides was negative (Figure 11). This either suggests that those who integrated Strava bike commuted less than their counterparts who chose to only self-report or only integrate some rides, or it indicates an over-reporting of bike commutes by self-reporters. With the requirement to report bike commuting to maintain the loaned bike, there is more reason to think the latter explanation is more plausible, especially given that Strava app integration is intended to streamline reporting and reduce participant burden for those participants who already use Strava. The effect of Strava was quite small for the participants who integrated Strava infrequently. But for those who used Strava for 100\% of their trip reporting (about $50 \%$ of people who used Strava at all did so for $100 \%$ of their trips), the model predicts they biked about 30\% less on average (an 18 percentage-point reduction). During the program, Strava integration was very rare (only 7\% of person-months included at least one Strava trip), making this effect not highly influential on program success if indeed Strava integration made it less likely for people to bike commute. However, if this effect is indicative of over-self-reporting of non-Strava users, then the program effects we summarize below may be upward biased by a considerable amount.

${ }^{5}$ https://bikesiliconvalley.org/wp-content/uploads/Google-Bike-Vision-Plan high res.pdf 
Figure 9. Model Predicted Mean Bike-to-Work Rate of Bike-Lending Participants by Commute Type

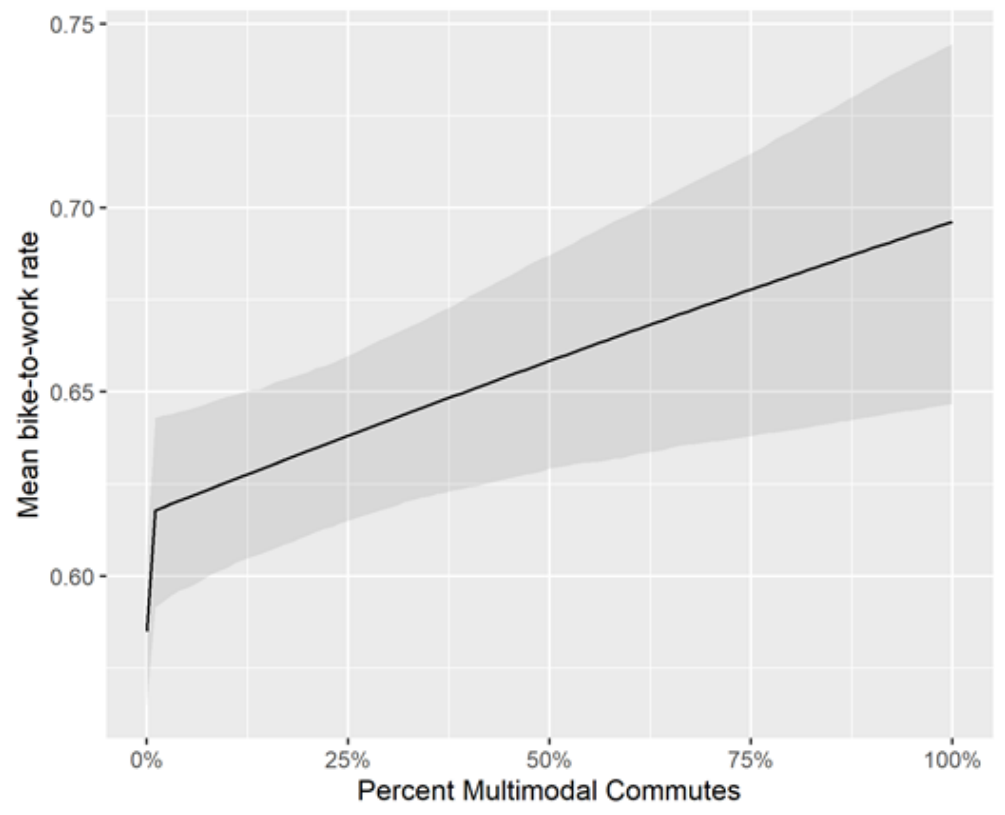

Figure 10. Model Predicted Mean Bike-to-Work Rate of Bike-Lending Participants by Self-Reported Bicycling Skill

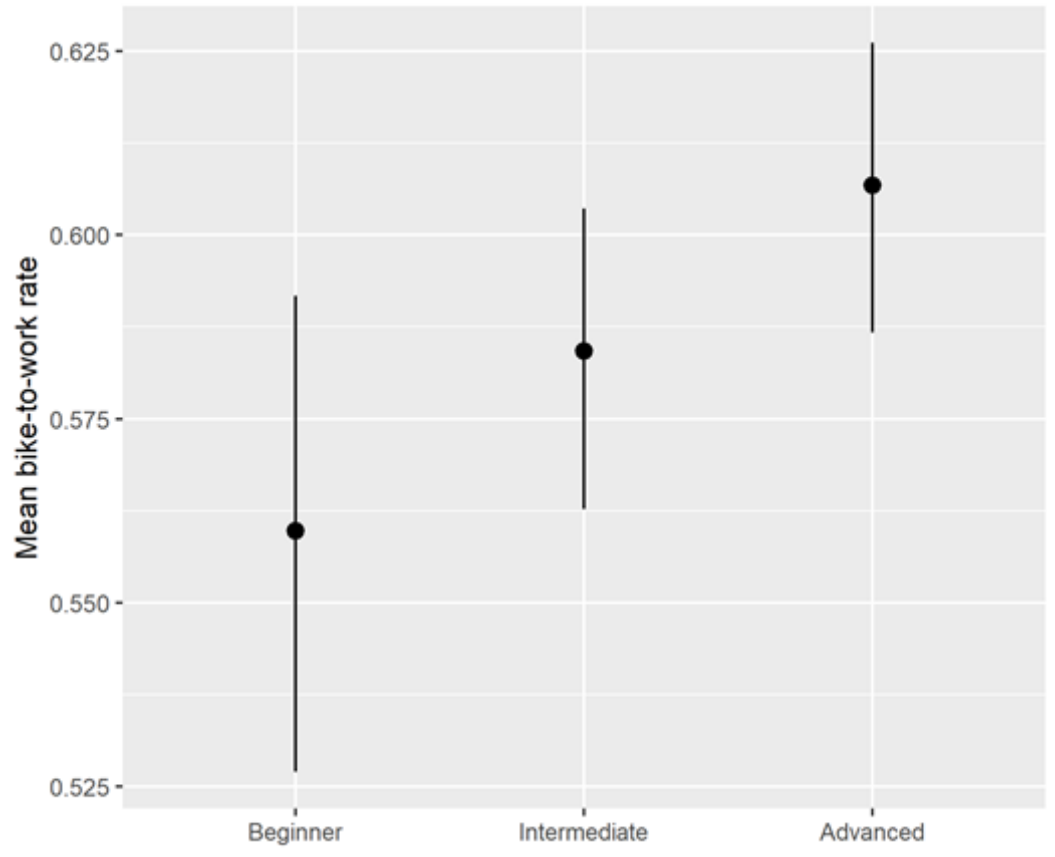


Figure 11. Model Predicted Mean Bike-to-Work Rate of Bike-Lending Participants by Use of Strava App Integration

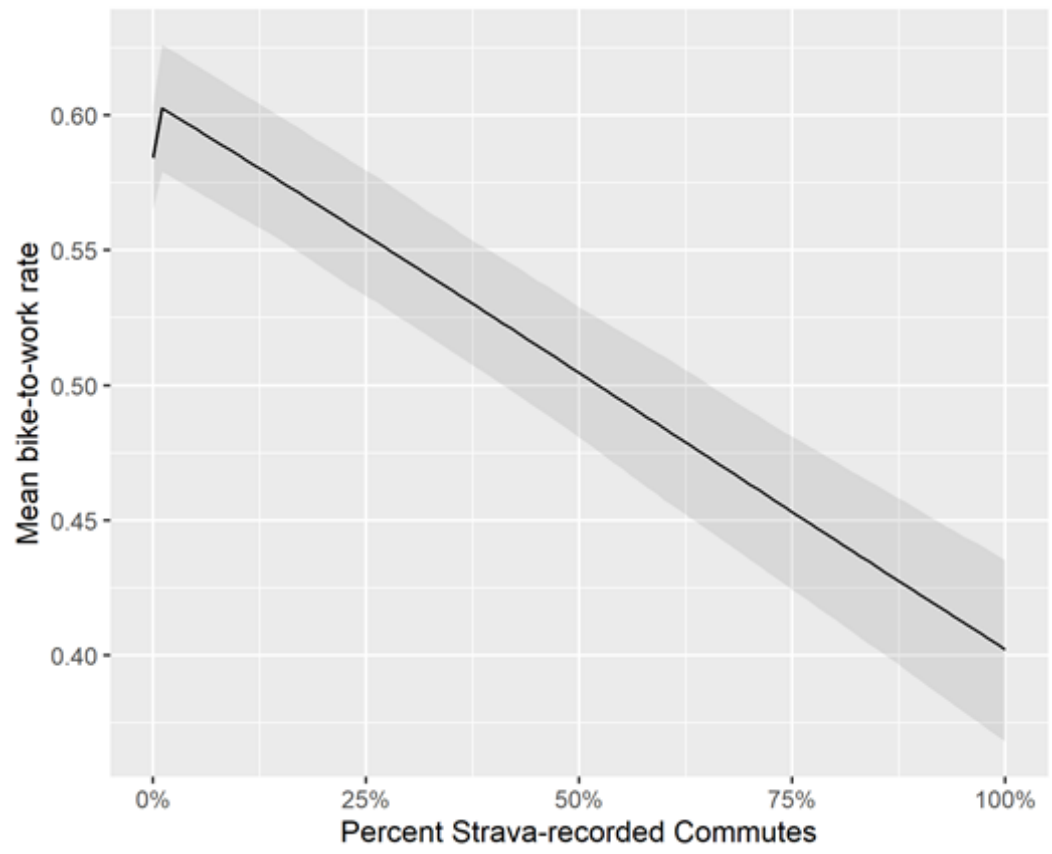

\subsection{Effects of the Program on Bicycling to Work}

We evaluated the effects of the program using the statistical model in two ways. First, we predicted the change in bicycling between the "before", "during", and "after" phases. This method assumes that there is no systematic bias in the trip reporting "before", "during", and "after" the program. Because not all participants had data in all periods, the uncertainty of the model predictions in the periods with less data is greater ("before" and "after" phases). Specifically, 956 participants (35\%) didn't record any before data. However, because the model uses all the data to learn person-level differences in bicycling in general, we still simulated predictions for all participants for each phase (Figure 12). Figure 12 shows the predicted mean bike-to-work rates as well as the person-level predictions in thin lines. When predicting the program's effect on bike commuting with only trip data, the results suggest an increase of more than 35 percentage points from "before" to "during" the program, and about 28 percentage points from "before" to "after" the program. This suggests that the program caused substantial gains in bicycling during the program but saw a portion of those gains retained after participants graduated from the program. However, because of the potential biases in the trip data during the "before" phase (see Section 3.2), we also report the program effects using a second method. 
Figure 12. Model Predicted Bike-to-Work Rate of Bike-Lending Participants by Intervention Phase from Trip Logs (Before, During, After)

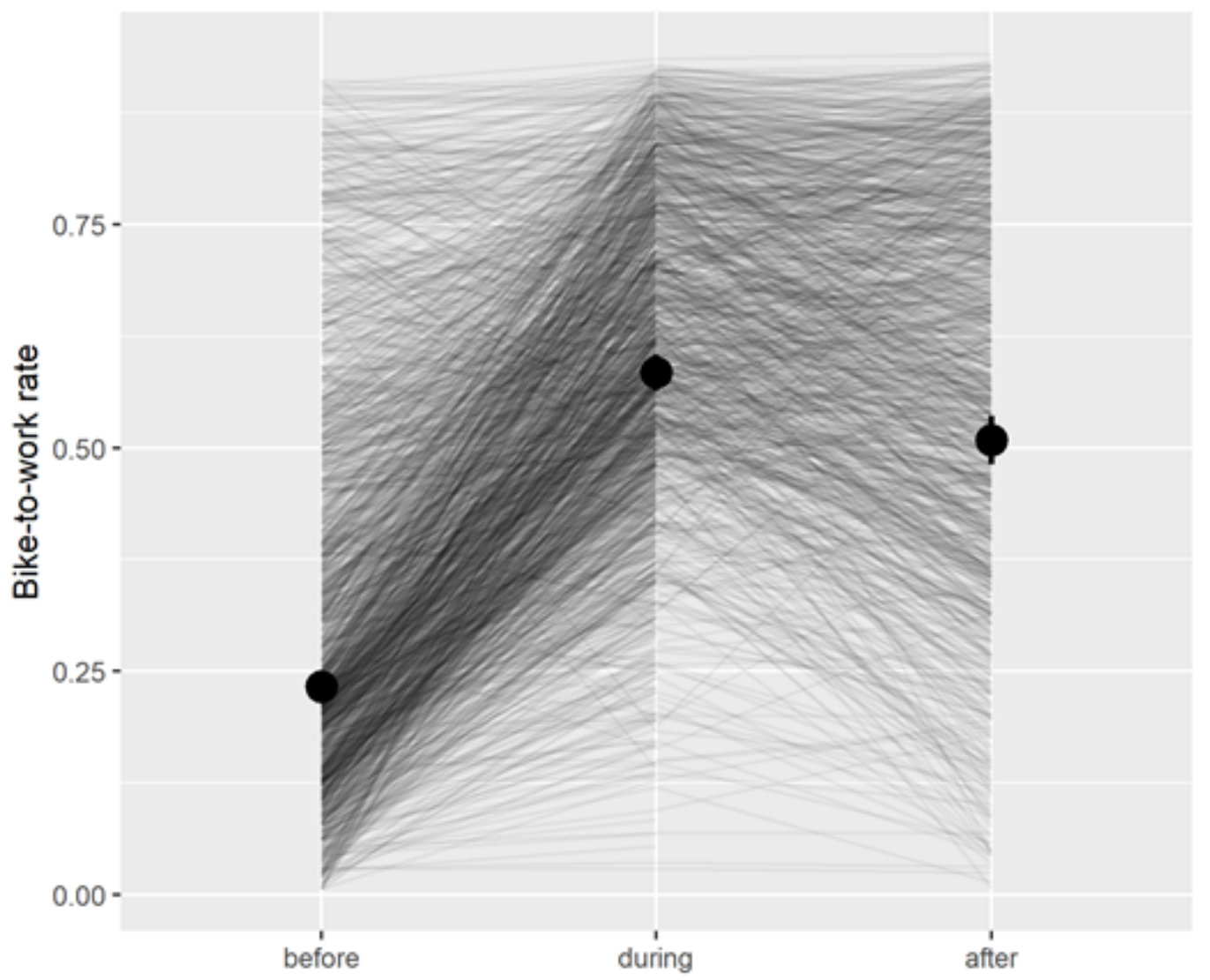

The second method we used was to compare the same person-level predictions for the "during" and "after" phases with the survey data before participation (Figure 13). Because so many participants claimed to never bike to work before the program started, this comparison shows even larger gains in bike commuting from the program. The benefit of this approach is that we have a unified general measure of bicycling right before the program. However, only 1656 of the 2712 participants (61\%) reported a before bike commute frequency making this approach systematically biased. Further, because we don't have model estimates for the before survey data, we can't predict before bike commuting for the missing responses like in the prior approach, which means Figure 13 only includes a subset of participants $(n=1656)$. Also, the applicants that did report bike commuting in the application may have been inclined to report less bicycling to work to increase their chances of getting a bike in the program (see Section 3.3). Nonetheless, using the survey as a baseline suggests that the program had a larger effect (close to 47 percentage point increase) on bike commuting than Figure 12 indicates. Realistically, the program effect is likely somewhere between the effects shown in Figures 12 and 13, although if the hypothesis that the Strava effect indicates a systematic self-reporting bias the effect could be roughly $30 \%$ less. In either analysis, including the potential over-reporting bias, the effects of the program on bicycling are clear. During program participation, bicycling to work is at its highest with more than $60 \%$ of commute 
trips occurring by bike on average for participants. After participants graduate, they bike to work less than during the program, but the models predict bike commuting still occurs greater than $50 \%$ of the time on average. This suggests that the program leads to some sustained behavior change. However, because we cannot assess the reliability of the after data, and because we suspect the after data may overestimate bicycling (see Section 3.2), we are less confident about the lasting effects of the program.

The caveats to these estimates and the need to consider alternative methods of estimation could be reduced with better data collection before and after program participation. Alternatively, making the program permanent (no graduation) is likely to achieve the greatest bike commuting from the program (see Section 6 for proposed program enhancements).

Figure 13. Model Predicted Bike-to-Work Rate of Bike-Lending Participants by Intervention Phase from Survey ("Before") and Trip Logs ("During", "After")

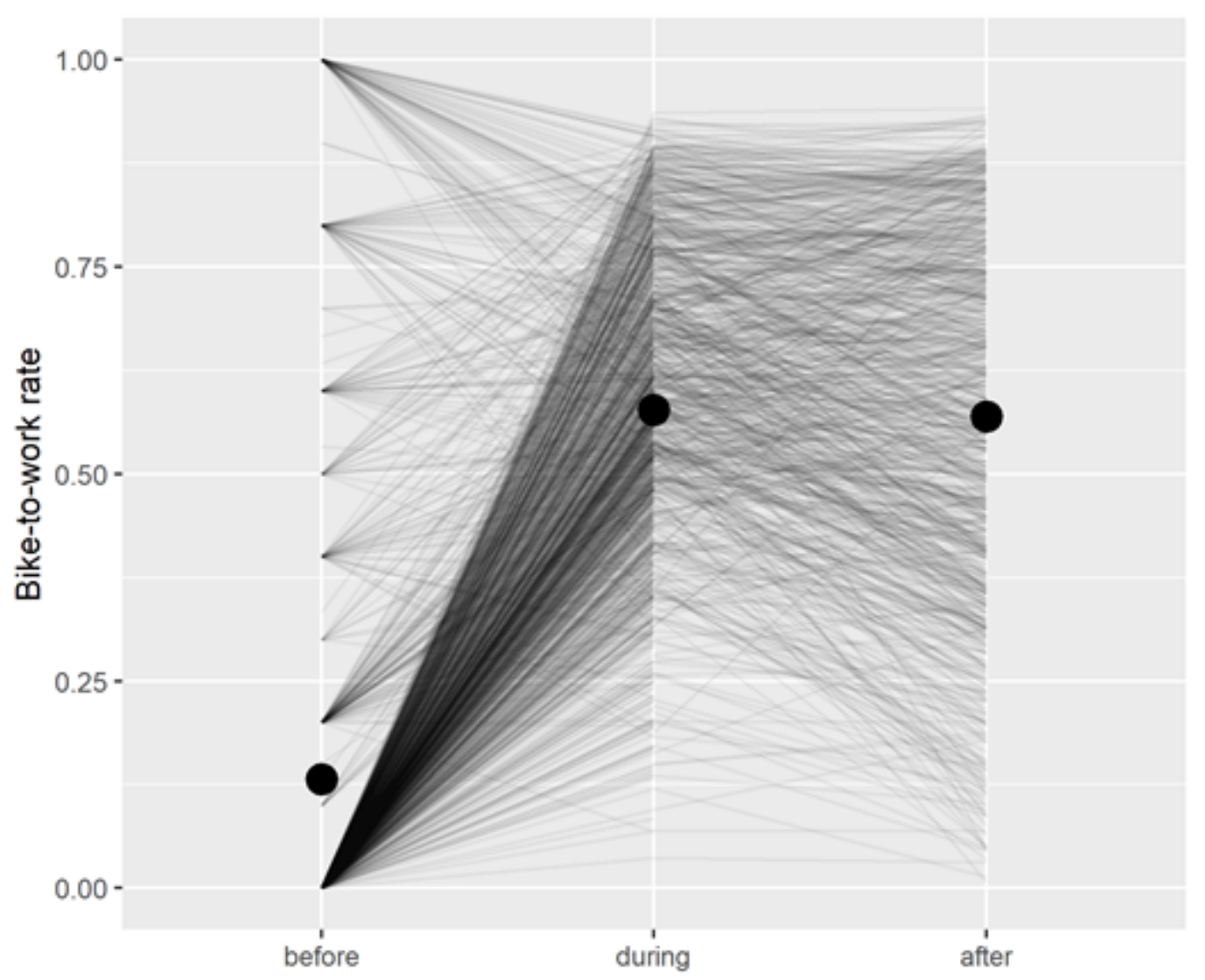

\subsection{Bicycling Distance Effects}

Another way to examine the benefits achieved from the program is to calculate the total bike commute miles gained from the program. When looking only at trip frequency, accessing downstream benefits such as increases in physical activity are difficult. By estimating increases in bike miles, the trip distances are accounted for, which makes for an easier calculation of benefits if 
desired. In this case we only consider the added bike miles from the commuting trips. This approach is probably a conservative estimate of the program's effect on bicycling overall because people may use their bike for many other trips outside of commuting. However, because we do not have data on other trips, and because TDM programs predominantly focus on commuting, we continue to focus only on commutes. To calculate the program induced bike commute miles, we simply multiplied the model predictions for bike commute frequency during the program by participants' self-reported commute distance, and then by two (assuming a two-way commute for all participants and ignoring multimodal commutes). Because most participants increased their bike commuting (Figure 13), their bike distance also increased. Most participants increased their total bike miles by about $5-15$ miles per week. The most frequent bike commuters tended to also have the shortest commutes, which is why so many had relatively small increases in bike commute miles. However, many more participants increased their bike miles by a much greater margin compared to those who reduced their bike miles (Figure 14).

Figure 14. Model Predicted Average Change in Bike Commute Miles Per Person Per Week Based on the Survey (Before) and Model Predicted Bike Commuting from Trip Logs (During)

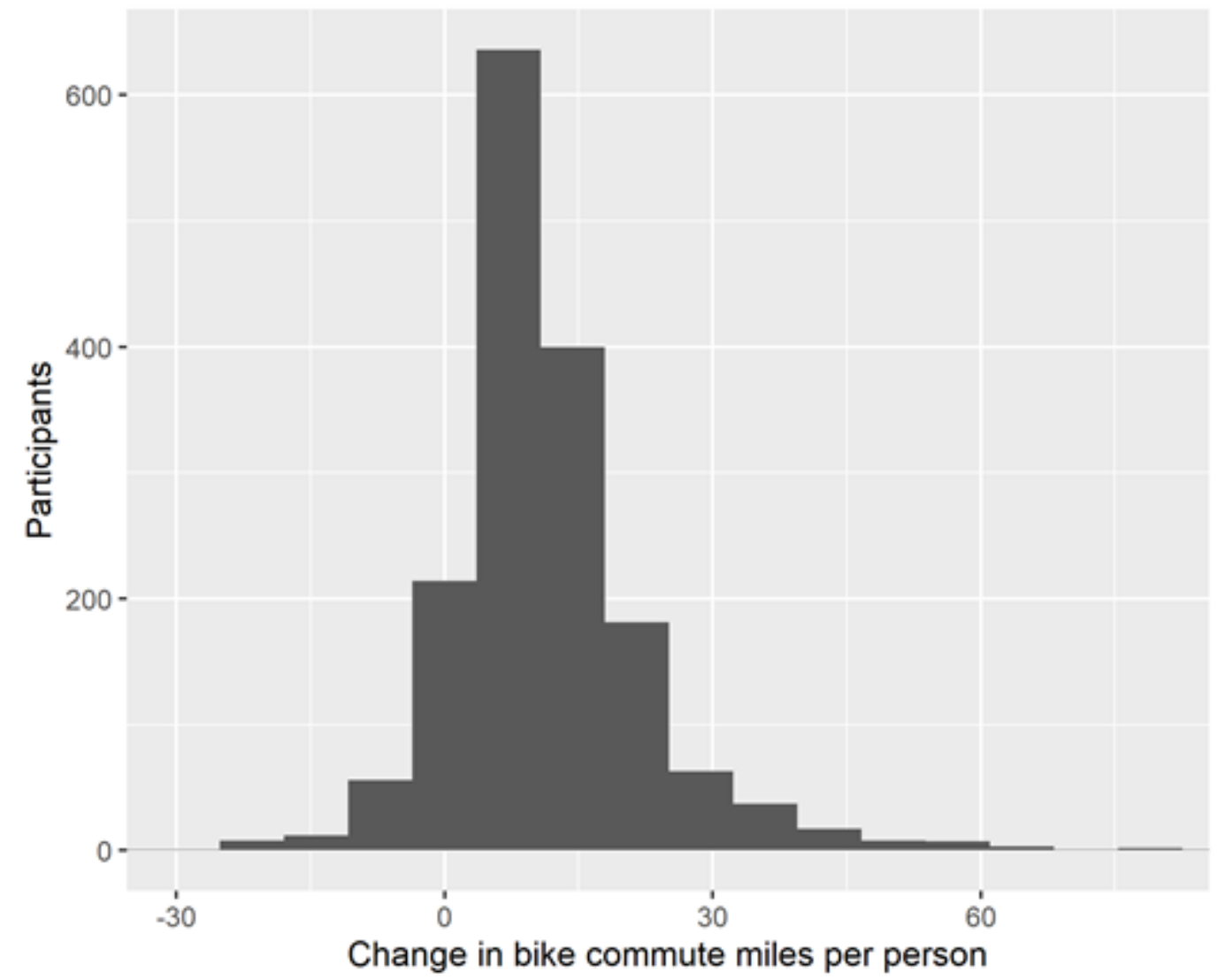




\subsection{Effects of the Program on SOV Commuting to Work}

We evaluated the reduction in SOV commuting from the program separately from the bicycling to work to consider the fact that not all bike commutes substituted for SOV commutes. Only a subset of participants (33\%) reported SOV trips during the program. Additionally, data on SOV trips before and after the program are unreliable because so few participants reported them. We are not clear why these participants reported all their travel to campus (and not just bike travel). It may be that they were not clear about the requirements and the form allowed them to report all modes, and so they did. To help ensure that the results are trustworthy, we used strong criteria for selecting data to include in the model (see Section 2.4).

Figure 15 shows the expected effects of the program on reducing SOV commuting based on the "before" application survey and the predicted SOV commuting rates during the program. Not surprisingly because the program initially targeted SOV commuters, the rate of SOV commuting dropped significantly during the program (a 55 percentage-point drop). Although there was some variation in the reduction in SOV commuting, the most common profile from this subset of participants was to go from an every-day SOV commuter to never SOV commuting. This suggests the program had a radical effect on commuting behavior for many people.

Figure 15. Model Predicted SOV-to-Work Rate of Bike-Lending Participants by Intervention Phase from Survey (Before) and Trip Logs (During)

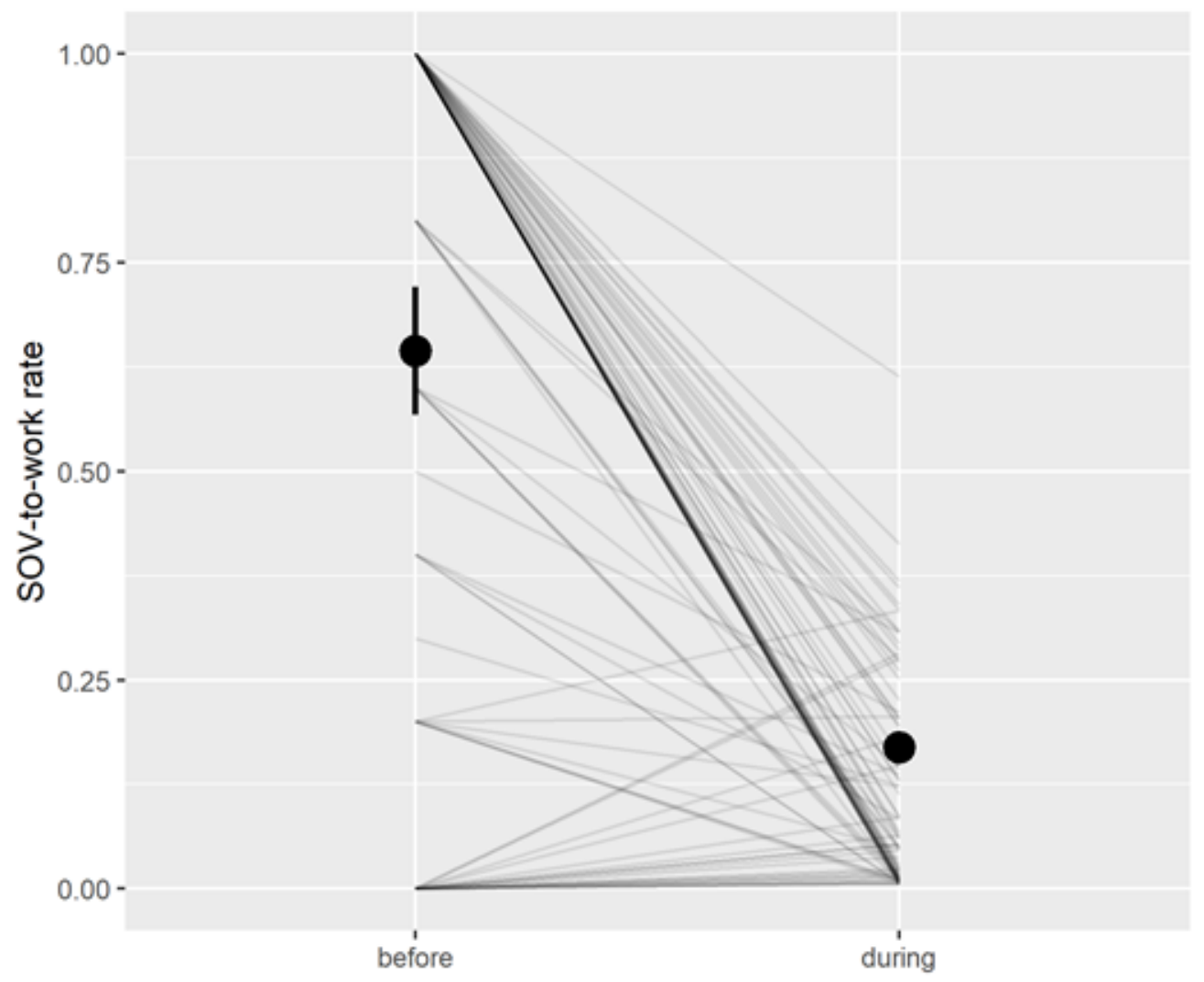


When multiplying the predictive change in SOV commuting by commuting distance (assuming round trips by the same mode), the results suggest that for each commute day, participants reduced about 6 miles of SOV driving on average but showed great variation in daily SOV miles reduced (Figure 16). Furthermore, when applying the expected SOV reduction rates across all the participants during the program, ${ }^{6}$ we estimate the program reduced a total of nearly 400,000 SOV commute miles from inception in mid-2015 through the end of 2019 (Figure 17).

These estimates have several limitations. First, the model predicted SOV commute reduction exceeded the model prediction bike commute increases. This could mean that the program caused people to give up SOV commuting even on days they didn't bike (e.g., by using transit, GBus, or carpooling). Alternatively, it could indicate a strong bias in the SOV reporting ("before" survey and/or "during" program trip logs). Second, because only a sub-sample of participants (33\%) were used to model SOV rates, we are predicting for a large out-of-sample group (67\% of our data); such predictions are likely biased in unquantifiable ways. However, our models account for some uncertainty in the estimation which is why the SOV reduction estimate has large confidence intervals (see shaded region in Figure 17).

Figure 16. Implied Daily SOV Miles Changes (During - Before) Per Person Based on Model Predicted SOV Rates and Self-Reported Commute Distances

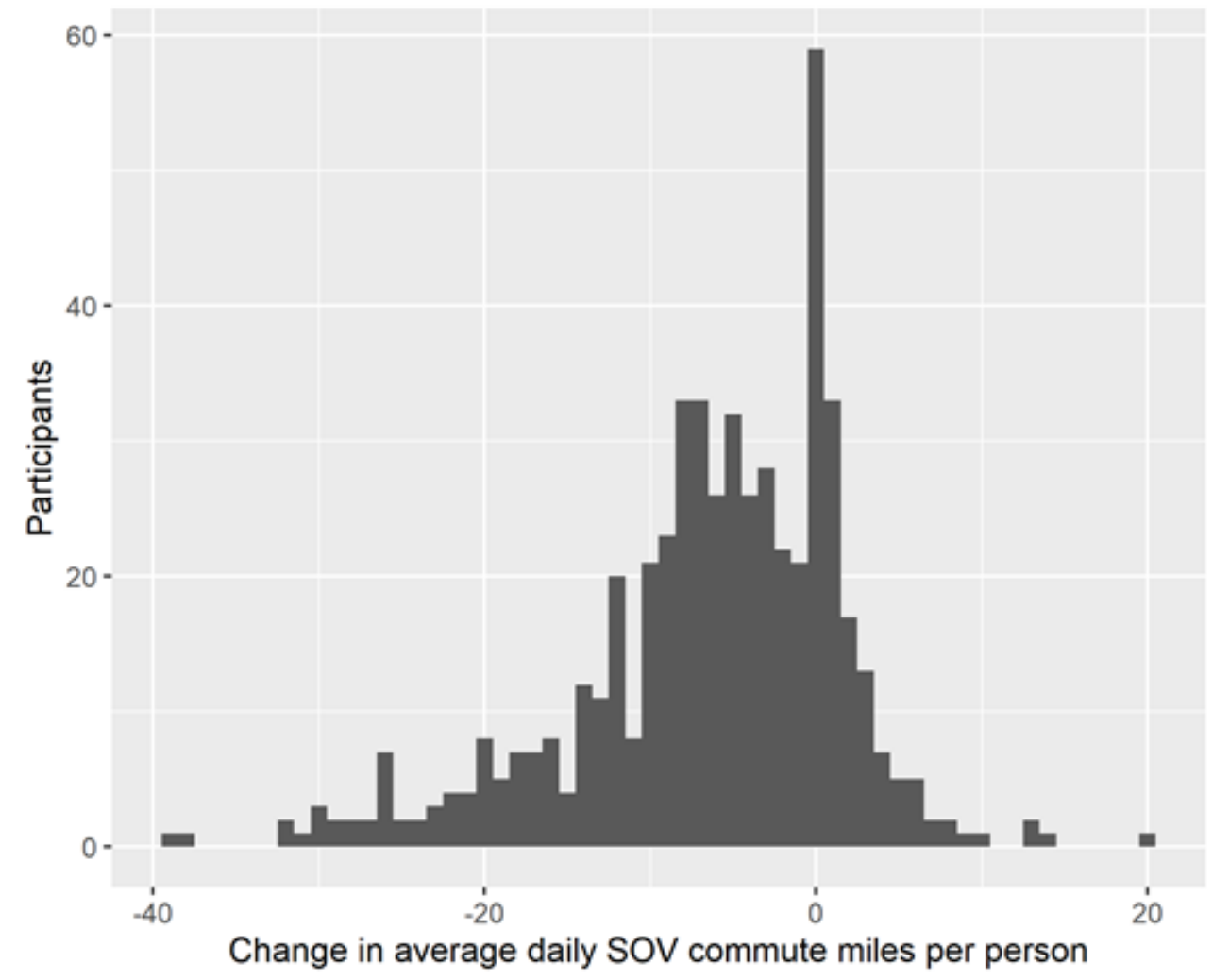

${ }^{6}$ This calculation uses the SOV reduction from the sub-sample and applies it to the entire program. 
Figure 17. Estimated Program-Level Cumulative Monthly SOV Miles Reduced Based on Model Predicted SOV Rates and Self-Reported Number of Commute Days and Commute Distance

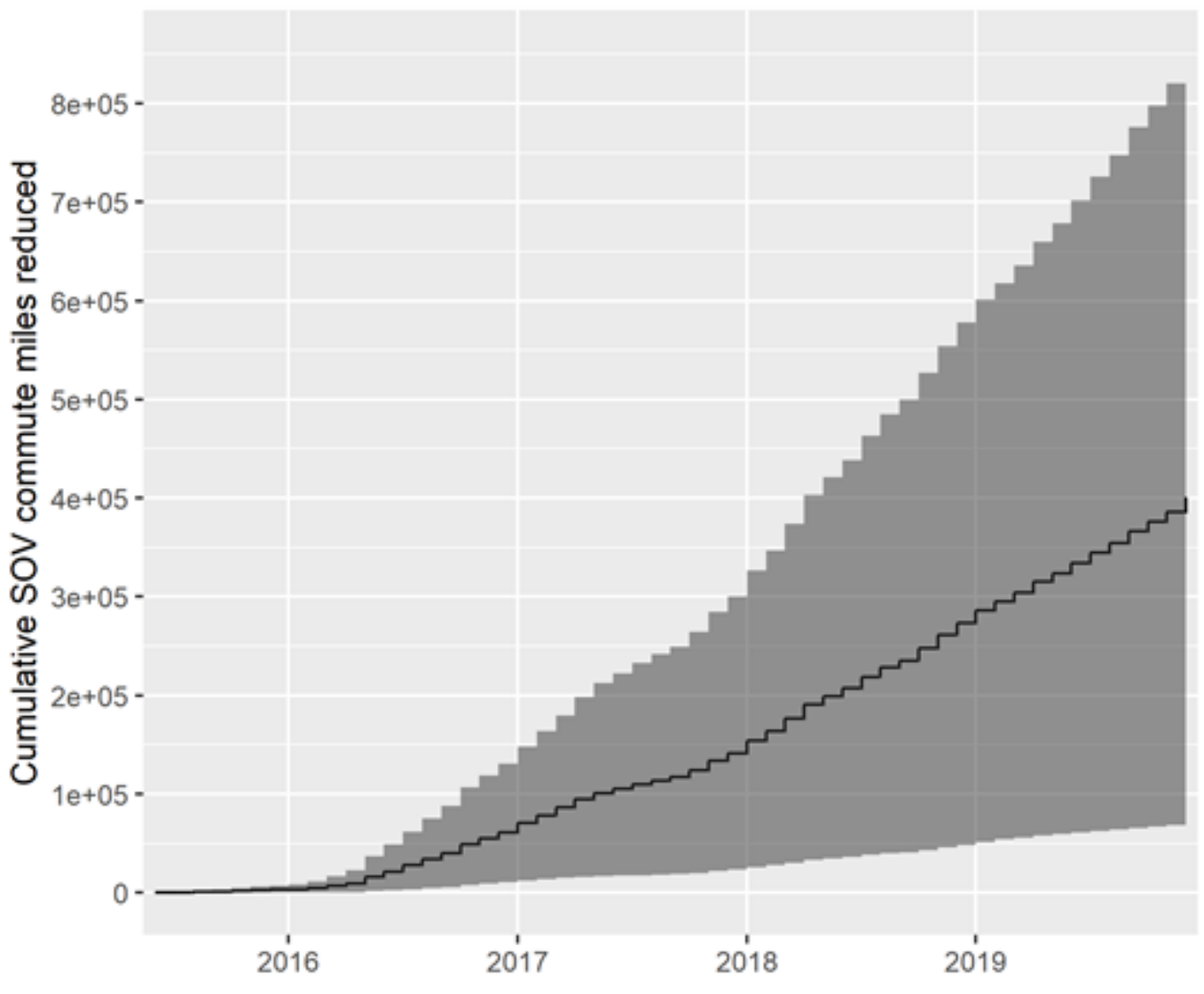

\subsection{Summary Program Effects}

Because of the complexity of the data, uncertainty in our model predictions, and the additional caveats described previously, we now simplify the expected effects to be used in future cost and benefit calculations. Table 5 reports the mean survey summary data and the model predictions for bicycling to work. This data indicates that the program on average increased bicycling frequency and miles ridden and depending on the selected baseline (survey or model predictions) the effects of the program may have been substantial (increase in more than 2 days biked to work per week per participant on average). Even if the model estimated "before" data is more accurate than the survey data, the effect is still nearly a 1 additional day of bicycling per week per participant during the program.

When considering the full range of benefits from such increases in bike commuting, the health benefits from physical activity are some of the strongest and directly relate to the increase in bike distance (not bike commute frequency). Table 5 shows that on average participants increased their bike distance during commutes by between 8.4 to 10.5 miles per week, depending on baseline 
measurement, and maintained a large increase in bicycling distance after graduation (between 6.6 and 8.7 miles per week). This equates to approximately 92,000 and 51,000 additional bike commute miles accrued annually during and after the program, respectively.

Both bike commute frequency and bike miles are substantially elevated after participants graduate from the program (Table 5). However, both statistics are lower than during program participation. This suggests that for some participants, the behavior change did not last after program graduation. There are many possible reasons for this decline, and some of them could be due to biased "after" data reporting. However, because the program offered an incentive to purchase a bike after the program, and not all participants used that incentive to purchase a bike (only $62 \%$ bought a bike after the program), we expect that the drop in bike commuting after the program is real. This bike buying rate is in the context of Google reducing the burdens of bike buying by bringing bike shops to their campuses for bike sale events and increasing the subsidy amount over time. Also, in the respondents who took the exit survey $(n=746)$, nearly $22 \%$ of them said they do not plan to bike commute after the program. Some included reasons that suggest potential improvements to the program (e.g., limited shower facilities, e-bikes too expensive) while other reasons will be more difficult for a TDM program to address (e.g., darkness and weather, road safety, need to shop on home-commute leg).

The SOV reduction is perhaps even more impressive than the bicycling increase. On average program participants went from more than 3 days of SOV commuting per week to less than 1 (a $75 \%$ reduction). This decline in SOV commuting equated to approximately 15 miles of reduced SOV driving to work for an average participant per week. 
Table 6. Surveyed and Modeled Bike-to-Work Days and Miles

\begin{tabular}{|l|c|c|c|c|}
\hline \multicolumn{1}{|c|}{ Outcome } & \multicolumn{2}{c|}{} & \multicolumn{2}{c|}{ Model Predicted Mean } \\
\hline \multicolumn{1}{|c|}{ Before Survey* } & Before** & During & After*** \\
\hline $\begin{array}{l}\text { Bike-To-Work Days Per } \\
\text { Participant-Week }\end{array}$ & 0.6 & 1.2 & 2.9 & 2.5 \\
\hline $\begin{array}{l}\text { Bike-To-Work Miles Per } \\
\text { Participant-Week }\end{array}$ & 3.4 & 5.5 & 13.9 & 12.1 \\
\hline $\begin{array}{l}\text { SOV-To-Work Days Per } \\
\text { Participant-Week }\end{array}$ & 3.2 & NA & 0.8 & NA \\
\hline $\begin{array}{l}\text { SOV-To-Work Miles Per } \\
\text { Participant-Week }\end{array}$ & 20.0 & NA & 5.0 & NA \\
\hline
\end{tabular}

* These estimates are likely biased downward because of applicants intentionally reporting less bike commuting to increase their chances of receiving a program bike.

** These estimates are likely biased upward because only prior bike commuters were reporting trip data before the program and the rates were much greater than the before survey data.

*** These estimates may be biased in either direction. Because it was not a requirement to record trips after the program, it is not clear why participants continued to report data and if that decision was correlated with bike commuting. 


\section{Proposed Future Analyses}

The project timeline and the scope limited our analyses to the most important program outcomes: changes in bike and SOV commuting. However, additional analyses have the potential to help inform more detailed strategies for maximizing the benefits of a bike and e-bike lending program. Below we list a few additional analyses that could be conducted along with their likely outcomes:

1) Visualization and analysis of commute origins and likely routes to work. Only a small fraction of participants reported their nearest cross-streets from their normal commute origin. Because of this we chose to ignore home location and general commute direction in our analysis. However, since perceived traffic safety and route directness are strong predictors of bicycling behavior, the results of the program might show some variation by home geographic region. A detailed analysis of the available data might help reveal some patterns of increased or decreased bike commuting which could help target future participants.

2) Qualitative analysis of participant survey data. The exit survey included a series of "write-in" survey questions on participant's experiences, perceptions, and satisfaction with the program. To better understand why the program didn't work for some and did for others, thematic coding of those "write-in" responses could be useful. Additional follow up interviews might be needed to clarify the true barriers to bicycling and help future programs identify strategies for helping employees overcome them. 


\section{Proposed Data Collection Enhancements}

We included a series of limitations of our analysis in Section 3.2. Many of these limitations related to the challenge of collecting "before" and "after" data for this program, but they also relate to TDM programs at large. The inability to collect precise "before" and "after" data makes it difficult to estimate the program effects with precision. Below are enhancements to participant reporting that could help improve the accuracy and precision of the program effects:

1) Enforce the reporting of all travel modes each week. While participants are required to report their travel each week, most of them only report their bicycling days. By not reporting other travel modes, this reduces the accuracy of program effects because mode choice cannot be analyzed, and because of a lack of reported "no commutes" which are not well represented in our analysis.

2) Conduct the same general travel survey (at least the matrix question about usual frequency of commuting days per week by mode) during program participation. This allows a simple comparison between "before", "during", and "after" travel. More importantly, because weekly travel is only reported during the program, by comparing the reported weekly travel to this general survey response, estimates of the accuracy of the general survey response can be made at the person-level. Once those accuracy assessments are made, person-level adjustments to the "before" and "after" data can be used to improve accuracy of the specific program effect on each participant. All of this can be done manually, or preferably within the modeling framework that we included in this report.

3) Create a simple experiment to examine the Strava effect. To better understand why participants who entirely used Strava for trip reporting bike much less frequently, incentivize nonStrava users to use Strava for a brief period of time to compare self-report to Strava integrated reporting. This experiment will require some careful planning to isolate the "Strava" effect through random recruitment and random (unknown to user) reporting for different weeks, but it will help to evaluate if over-reporting is a rampant program problem.

4) Find a way to encourage after (exit) survey participation. To better understand the lasting effects of the program, a larger share of participants should provide "after" data. This could be done through additional incentives.

5) Find a way to measure "before" and "after" trip data (not just general survey data). This suggestion is perhaps asking too much of TDM programs. It would require interested employees to record their travel before they receive the incentive (bike or e-bike) and may discourage them from applying in the first place. An alternative approach would be to 
integrate survey responses from the annual campus travel surveys ${ }^{7}$ which are not directly linked to any TDM program. Those responses are less likely to include social desirability or strategic response biases.

${ }^{7}$ Campus travel surveys are often anonymous, making linking them to specific program participants difficult if not impossible. 


\section{Policy Recommendations}

The following recommendations are based on the behavioral analysis and represent potential ways to increase bike commuting. These recommendations do not consider the downstream benefits of increasing bike commuting nor the cost effectiveness of such recommendations.

1) Consider a permanent lending program with no graduation. Given that bike commuting was at its highest during the program and that bike commute rates dropped after graduation, keeping the program running (indefinite bike and e-bike lending) could be a good strategy to maintain the bike commuting behavior. This approach would probably need to be paired with TDM managers following through with collecting the bikes if the participants are not meeting the reporting requirements or other disciplinary or encouragement strategies. However, the stated bike commute rate (60\%) could still differ from the rate management uses to implement any action.

2) Consider alternative vehicle form factors. Because of the rapid growth in micro-mobility, new form factors for bikes, e-bikes, and e-scooters are emerging. While it may be a challenge to keep up with the advances in vehicle technology, providing a greater variety of vehicle types might help increase participation (e.g., cargo bikes, folding bikes). Many respondents decrease their bike commuting in the wet season, so vehicles that provide some level of protection against the rain could be beneficial.

3) Consider added benefits of outfitting participants with accessories and clothing to make regular bike commuting safer and more comfortable. This could include integrated lights, wheel lights (for horizontal visibility), rack bags or baskets, subsidies for rain gear, etc. Many of these added benefits could be provided on campuses during bike sale events.

4) Consider finding ways to increase multimodal bike commutes. The analysis suggests that participants who use their bike for at least some multimodal commutes end up doing so slightly more often than participants who only direct commute with their bike. Potential target employees could be car commuters who live farther than walking distance to transit and GBus stops, but who could do so easily with a bike. This recommendation also relates to recommendation \#2 (alternative vehicle form factors). Folding bikes and light-weight e-bikes may be required to bring about this type of shift in commute behavior.

5) Try to target non-bike commuters if possible. Non-bike commuters saw the largest gains from this program, while participants who already bike commuted, even if irregularly, saw smaller gains.

6) Continuing to work with cities to make routes to work safe and stress free will likely provide a growing pool of interested participants. Although infrastructure is not considered in this study, the lack of bike infrastructure and safe bicycling routes to the two Google campuses 
are clear barriers to biking that should be addressed to allow more people to consider this program.

7) Consider non-bike policies that can increase employees' likelihood to bike commute. This includes policies that make driving more expensive (e.g., price parking, parking cash-out) and policies that encourage living closer to work or closer to safe bike routes to work. 


\section{Bibliography}

Armstrong, E. P. (2010). Bike sharing: a randomized study evaluating the University of Oregon bike load program. University of Oregon.

Dill, J. (2009). Bicycling for transportation and health: the role of infrastructure. Journal of Public Health Policy, 30 Suppl 1(1), S95-110. https://doi.org/10.1057/jphp.2008.56

Fitch, D. T. (2019). Electric Assisted Bikes (E-bikes) Show Promise in Getting People out of Cars. Policy Brief. Institute of Transportation Studies, University of California, Davis. Retrieved from https://escholarship.org/uc/item $/ 3 \mathrm{~mm} 040 \mathrm{~km}$

Fowler, S. L., Berrigan, D., \& Pollack, K. M. (2017). Perceived barriers to bicycling in an urban U.S. environment. Journal of Transport \& Health, 6(March), 474-480. https://doi.org/10.1016/j.jth.2017.04.003

Fyhri, A., \& Beate Sundfør, H. (2020). Do people who buy e-bikes cycle more? Transportation Research Part D: Transport and Environment, 86, 102422. https://doi.org/10.1016/j.trd.2020.102422

Fyhri, A., \& Fearnley, N. (2015). Effects of e-bikes on bicycle use and mode share. Transportation Research Part D: Transport and Environment, 36, 45-52. https://doi.org/10.1016/j.trd.2015.02.005

Fyhri, A., Sundfør, H. B., \&Weber, C. (2016). Effect of subvention program for electric bicycle in Oslo on bicycle use, transport distribution and $\mathrm{CO}_{2}$ emissions. TØI Report, 1498, 114.

Handy, S. L., \& Fitch, D. T. (2020). Can an e-bike share system increase awareness and consideration of e-bikes as a commute mode? Results from a natural experiment. International Journal of Sustainable Transportation, 0(0), 1-16. https://doi.org/10.1080/15568318.2020.1847370

Handy, S. L., Xing, Y., \& Buehler, T. (2010). Factors associated with bicycle ownership and use: a study of six small U.S. cities. Transportation, 37, 967-985. https://doi.org/10.1007/s11116-010-9269-x

Haubold, H. (2016). Electromobility for all: Financial incentives for e-cycling. European Cyclists' Federation.

Heinen, E., van Wee, B., \& Maat, K. (2010). Commuting by bicycle: an overview of the literature. Transport Reviews, 30(1), 59-96. https://doi.org/10.1080/01441640903187001 
Lally, P., Van Jaarsveld, C. H. M., Potts, H. W. W., Wardle, \& Jane. (2010). How are habits formed: Modelling habit formation in the real world. European Journal of Social Psychology Eur., 40, 998-1009. https://doi.org/10.1002/ejsp

Lamy, V. (2001). Electric Bike 2000, 46.

Litman, T. (2021). Evaluating Active Transport Benefits and Costs: Guide to valuing walking and cycling improvements and encouragement programs. Victoria Transport Policy Institute. Victoria Transport Policy Institute. Retrieved from https://www.vtpi.org/nmt-tdm.pdf

MacArthur, J., Dill, J., \& Person, M. (2014). Electric bikes in North America: Results of an online survey. Transportation Research Record, 2468, 123-130. https://doi.org/10.3141/2468$\underline{14}$

MacArthur, J., Harpool, M., Scheppke, D., \& Cheery, C. R. (2018). A North American survey of electric bicycle owners. NITC-RR-1041.

MacArthur, J., \& Kobel, N. (2016). Evaluation of an Electric Bike Pilot Project at Three Employment Campuses in Portland, Oregon. Transportation Research Board, 95th Annual Meeting, (August 2015), 19. https://doi.org/10.15760/trec.158

McCoy, K., Andrew, J., \& Lyons, W. (2016). Ridesharing, Technology, and TDM in University Campus Settings: Lessons for State, Regional, and Local Agencies. FHWA-HEP-16$060 . \quad$ Retrieved from https://rosap.ntl.bts.gov/view/dot/12297\%0Ahttps://trid.trb.org/view/1414860

Nozick, L. K., Borderas, H., \& Meyburg, A. H. (1998). Evaluation of travel demand measures and programs: A data envelopment analysis approach. Transportation Research Part A: Policy and Practice, 32(5), 331-343. https://doi.org/10.1016/S0965-8564(97)00043-8

Ramezani, S., Hasanzadeh, K., Rinne, T., Kajosaari, A., \& Kyttä, M. (2021). Residential relocation and travel behavior change: Investigating the effects of changes in the built environment, activity space dispersion, car and bike ownership, and travel attitudes. Transportation Research Part A: Policy and Practice, 147, 28-48. https://doi.org/10.1016/j.tra.2021.02.016

Shoup, D. C. (1997a). Evaluating the effects of cashing out employer-paid parking: Eight case studies. Transport Policy, 4(4), 201-216.

Shoup, D. C. (1997b). The High Cost of Free Parking. Journal of Planning Education and Research, 17(1), 3-20. https://doi.org/10.1177/0739456X9701700102

Sundfør, H. B., \& Fyhri, A. (2017). A push for public health: The effect of e-bikes on physical activity levels. BMC Public Health, 17(1), 1-12. https://doi.org/10.1186/s12889-017$\underline{4817-3}$ 
Xing, Y., Handy, S. L., \& Mokhtarian, P. L. (2010). Factors associated with proportions and miles of bicycling for transportation and recreation in six small US cities. Transportation Research Part D: Transport and Environment, 15(2), 73-81. 


\section{About the Authors}

\section{Dillon T. Fitch}

Dillon is a Research Faculty member and the Co-Director of the BicyclingPlus Research Collaborative at the Institute for Transportation Studies, UC Davis. His research focuses on bicycling behavior and micromobility services.

\section{Zeyu Gao}

Zeyu Gao was a graduate student researcher in Civil and Environmental Engineering at UC Davis and now works as an engineer for Caltrans District 10.

\section{Lucy Noble}

Lucy is the Transportation Demand Management Program Manager at Google. Her efforts are focused on reducing traffic and parking demand at their headquarters in Silicon Valley by designing and implementing innovative commute options for commuters. She uses findings from behavioral science research to nudge commuters to shift to, or sustain, non-driving commutes.

\section{Terry Mac}

Terry is the Senior Manager of Operations for Hallcon managing Google's Bike Programs. He executes the strategy for commuter and bikeshare programs, including implementing and marketing effective communication and program management to reduce vehicle trips to support Google's sustainability goals. 


\section{Hon. Norman Y. Mineta}

\section{MTI BOARD OF TRUSTEES}

Founder, Honorable

Norman Mineta*

Secretary (ret.),

US Department of Transportation

Chair,

Will Kempton

Retired Transportation Executive

Vice Chair,

Jeff Morales

Managing Principal

InfraStrategies, LLC

Executive Director, Karen

Philbrick, $\mathrm{PhD}^{*}$

Mineta Transportation InstituteSan

José State University

Winsome Bowen

Vice President, Project Development Strategy

WSP

David Castagnetti

Co-Founder

Mehlman Castagnetti Rosen \&

Thomas

Maria Cino

Vice President, America \& U.S.

Government Relations

Hewlett-Packard Enterprise

Grace Crunican**

Owner

Crunican LLC

Donna DeMartino

Managing Director

Los Angeles-San Diego-San Luis

Obispo Rail Corridor Agency
John Flaherty

Senior Fellow

Silicon Valley American Leadership

Forum

Stephen J. Gardner*

President \& CEO

Amtrak

Rose Guilbault

Board Member

Peninsula Corridor Joint Power

Board

Kyle Holland

Senior Director, Special Projects, TAP

Technologies, Los Angeles County

Metropolitan Transportation Authority

(LA Metro)

Ian Jefferies*

President \& CEO

Association of American Railroads

Diane Woodend Jones Principal

\& Chair of Board

Lea \& Elliott, Inc.

Elissa Konove*

Acting Secretary

California State TransportationAgency

(CALSTA)

Therese McMillan

Executive Director

Metropolitan Transportation

Commission (MTC)

Abbas Mohaddes

President \& COO

Econolite Group Inc.

Stephen Morrissey

Vice President - Regulatory and

Policy

United Airlines
Dan Moshavi, PhD*

Dean

Lucas College and GraduateSchool of

Business, San José State University

Toks Omishakin*

Director

California Department of

Transportation (Caltrans)

Takayoshi Oshima

Chairman \& CEO

Allied Telesis, Inc.

Greg Regan

President

Transportation Trades Department, AFL-CIO

Paul Skoutelas*

President \& CEO

American Public Transportation

Association (APTA)

Kimberly Slaughter

CEO

Systra USA

Beverley Swaim-Staley

President

Union Station Redevelopment

Corporation

Jim Tymon*

Executive Director

American Association of State

Highway and Transportation

Officials (AASHTO)

$*=$ Ex-Officio

** $=$ Past Chair, Board of Trustees

\section{Directors}

Karen Philbrick, PhD

Executive Director

Hilary Nixon, PhD

Deputy Executive Director

Asha Weinstein Agrawal, PhD

Education Director

National Transportation Finance Center Director

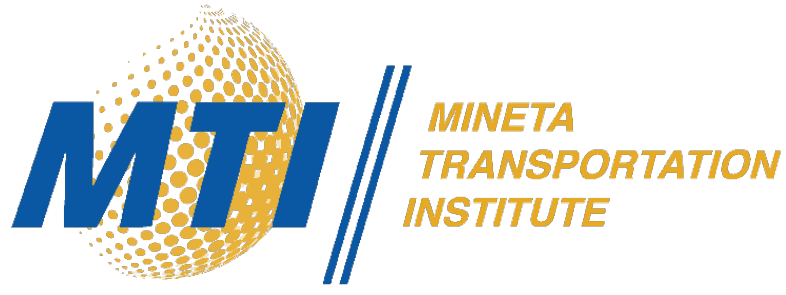

Brian Michael Jenkins

National Transportation Security Center Director 